\title{
EXPOSURE TO ENVIRONMENTAL AND LIFESTYLE FACTORS AND ATTENTION-DEFICIT / HYPERACTIVITY DISORDER IN CHILDREN - A REVIEW OF EPIDEMIOLOGICAL STUDIES
}

\section{KINGA POLAŃSKA, JOANNA JUREWICZ, and WOJCIECH HANKE}

Nofer Institute of Occupational Medicine, Łódź, Poland

Department of Environmental Epidemiology

\begin{abstract}
Attention-deficit/hyperactivity disorder (ADHD) is one of the most common neurodevelopmental disorders in children. Although the mechanisms that lead to the development of ADHD remain unclear, genetic and environmental factors have been implicated. These include heavy metals and chemical exposures, nutritional and lifestyle/psychosocial factors. The aim of this review was to investigate the association between $\mathrm{ADHD}$ or ADHD-related symptoms and widespread environmental factors such as phthalates, bisphenol A (BPA), tobacco smoke, polycyclic aromatic hydrocarbons (PAHs), polyfluoroalkyl chemicals (PFCs) and alcohol. Medline, PubMed and Ebsco search was performed to identify the studies which analyze the association of prenatal and postnatal child exposure to environmental toxicants and lifestyle factors and ADHD or ADHD-related symptoms. The review is restricted to human studies published since 2000 in English in peer reviewed journals. Despite much research has been done on the association between environmental risk factors and ADHD or ADHD symptoms, results are not consistent. Most studies in this field, focused on exposure to tobacco smoke, found an association between that exposure and ADHD and ADHD symptoms. On the other hand, the impact of phthalates, BPA, PFCs, PAHs and alcohol is less frequently investigated and does not allow a firm conclusion regarding the association with the outcomes of interest.
\end{abstract}

Key words:

Children, Environmental toxicants, Attention-deficit/hyperactivity disorder, Inattention, Impulsivity

\section{INTRODUCTION}

Attention-deficit / hyperactivity disorder (ADHD) is one of the most common neurodevelopmental disorders in children, with an estimated pooled worldwide prevalence in children and adolescents of 5.3\% (95\% CI: 5.0 5.6) [1]. When the children are considered alone, the range for prevalence is about $5-10 \%$, whereas when adolescents are considered by themselves, the range is lower (about 2.5-4\%) [1,2]. Like many other childhoodonset behavioural disorders, ADHD is diagnosed more frequently in boys than girls [3,4]. Children diagnosed with ADHD are a heterogeneous population sharing common symptoms, including inattention, impulsivity, and, in some cases, hyperactivity, or a combination of

This study was performed under the project "Prenatal and postnatal exposure to tobacco smoke, PAHs and heavy metals and the risk of respiratory diseases, allergy and poor mental and physical development" supported by the grant PNRF-218-AI-1/07 from Norway through the Norwegian Financial Mechanism within the PolishNorwegian Research Fund and project "Phthalate exposure and birth outcome and child neurodevelopment" supported by the grant UMO-2011/01/B/NZ7/06462 from National Science Centre.

Received: May 8, 2012. Accepted: July 6, 2012.

Address reprint request to K. Polańska, Nofer Institute of Occupational Medicine, Department of Environmental Epidemiology, św. Teresy 8, 91-348 Łódź, Poland (e-mail: kinga@imp.lodz.pl). 
the symptoms. Inattention is identified when child is easily distracted and unable to keep his/her mind on single task for extended periods of time. Impulsivity can be recognized by lack of control or restraint and hyperactivity by child's constant restlessness. Children with ADHD are at increased risk for conduct disorder, antisocial behaviour and drug abuse later in life $[3,5,6]$. Although the mechanisms that lead to the development of ADHD remain unclear, genetic and environmental factors have been implicated. These include heavy metals and chemical exposures, nutritional and lifestyle/ psychosocial factors.

This paper reviews the literature published since 2000 investigating the association between ADHD or ADHDrelated symptoms and widespread environmental factors such as phthalates, bisphenol A (BPA), tobacco smoke, polycyclic aromatic hydrocarbons (PAHs), polyfluoroalkyl chemicals (PFCs) and alcohol.

\section{Criteria for inclusion of studies into the review}

Medline, PubMed and Ebsco search was performed to identify the studies which analyze the association of prenatal and postnatal child exposure to widespread environmental toxicants and ADHD or ADHD-related symptoms. Relevant studies were also identified via review of references cited in all published studies. The review is restricted to human studies published since 2000 in English in peer reviewed journals. The following keywords were used to identify relevant papers: ADHD, hyperactivity, inattention, impulsivity, pregnancy, prenatal period, child, environment, environmental exposures, chemicals, lifestyle factors, maternal smoking, passive smoking, PAHs, phthalates, BPA, PFCs and alcohol. For each factor we reviewed:

- study design and population,

- sources of exposure and methods used for its assessment,

- assessment of ADHD or ADHD-related symptoms,
- confounding factors included in analysis,

- the proposed mechanism by which the exposure is linked with ADHD-related neurobehavioural changes. Out of total 72 articles identified, 40 meet eligibility criteria and have been included in the present review.

\section{PHTHALATES AND ADHD OR ADHD SYMPTOMS}

Phthalates are a family of industrial chemicals that have been used for a variety of purposes. They are added to plastics applied in the manufacture of children's toys and medical devices to make them soft and flexible as well as added to cosmetics as a vehicle for fragrance. Because phthalates are ubiquitous in daily life, the potential consequences of human exposure to phthalates have raised concerns in the general population. Animal studies have also reported that some phthalates might cause hyperactivity similar to the clinical syndrome of ADHD found in children [7].

Several mechanisms of adverse neurodevelopmental outcomes in humans exposed to phthalates are postulated. Phthalates may interfere with the thyroid hormone system [8,9], lipid signal transduction pathways [10], decrease the number of midbrain dopaminergic neurons, reduce tyrosine hydroxylase biosynthetic activity [11] and tyrosine hydroxylase immunoreactivity [12], and exhibit antiandrogenic activity [13]. Phthalates have been shown to cause hyperactivity in rats, possibly through effects on the dopamine system $[12,14]$.

The first studies investigating the relationship between prenatal phthalate exposure and ADHD-related behaviours and ADHD were published by Engel et al. [15,16] and Kim et al. [17] (Table 1). In the study performed among neonates enrolled into a multiethnic birth cohort at the Mount Sinai School of Medicine in New York City, maternal urinary concentrations of phthalate metabolites and neonatal behaviour measured within 5 days of birth were evaluated. There were strong, inverse associations 
between increasing levels of high molecular weight phthalate metabolites (monobenzyl phthalate (MBzP), mono-(2-ethyl-5-carboxypentyl) phthalate (MECPP), mono-(2-ethyl-5-hydroxylhexyl) phthalate (MEHHP), mono-(2-ethyl-5-oxohexyl) phthalate (MEOHP), mono-(2-ethylhexyl) phthalate (MEHP), mono-(3-carboxypropyl) phthalate (MCPP)) and attention and orientation scores among girls. Similarly, there was an inverse association between high molecular weight metabolite concentrations and quality of alertness scores among girls [15]. The association of prenatal phthalate exposure with behaviour and executive functioning at 4-9 years of age in the same cohort of children was examined. However, in multivariate adjusted models, increasing $\log _{\mathrm{e}}$ concentrations of low molecular weight phthalate metabolites (monobutyl phthalate (MBP), monoethyl phthalate (MEP), monoisobutyl phthalate (MiBP), monomethyl phthalate (MMP)) were significantly associated only with conduct problems [16].

In childhood, exposures to DEHP metabolites were associated with ADHD in a cross-sectional study of South Korean children between the ages of 8 and 11 years. Significant relationship was also observed between the urine concentrations of metabolites of dibutyl phthalate (DBP) and the number of omission and commission errors in continuous performance tests [17].

As there are only three studies which suggest that exposure to phthalates is associated with ADHD [17] and ADHD behaviours: conduct problems [16] and concentration or orientation [15], it is very difficult to arrive at a conclusion and additional research is necessary.

\section{BISPHENOL A AND ADHD OR ADHD SYMPTOMS}

Bisphenol A (BPA) is produced in large quantities and used primarily to manufacture polycarbonate plastics and epoxy resins; it is considered to show weak oestrogen-like properties.
BPA might disrupt the endocrine system [18]. Experimental studies with animals indicated that gestational BPA exposure disrupts normal neurodevelopment, affecting sexually dimorphic behaviours such as aggression, anxiety, exploration, and spatial memory [19-21]. BPA may alter the course of normal neurodevelopment by the impact on neuronal connectivity, distribution of serotonergic fibres, synaptic function, and dendritic length [22]. The effect of exposure to BPA and ADHD behaviours were examined only in two studies performed in the United States $[23,24]$ (Table 1). In the study in Cincinnati, Ohio, among 249 mothers and their children, maternal urine was collected around 16 and 26 weeks of gestation and at birth to measure the level of bisphenol A. An association between mean prenatal BPA concentrations and externalizing scores in females was observed. The strongest association was found between early (below 16 weeks of gestation) urinary BPA concentrations and externalizing scores [23]. The same author continued the study and examined the children at 3 years of age [24]. Gestational BPA exposure was associated with higher scores for measures of anxiety, hyperactivity, emotional control, and behavioural inhibition. Similar to previous findings [23], the effects of gestational BPA exposure on these behavioural domains were larger among girls than boys [24].

Summing up, in the reported studies the exposure to BPA was associated with ADHD behaviours like externalizing problems [24] and anxiety, hyperactivity, weaker emotional control, and impaired behavioural inhibition [24].

However, as noted by Longnecker [25], the results need careful consideration as the hyperactivity and aggression are externalizing behaviours more frequent in boys than in girls [26,27]. Sexually dimorphic behaviours in female rodents have been shown to be masculinized by exogenous estrogens [28], and BPA is weakly estrogenic in most experimental systems [29]. 


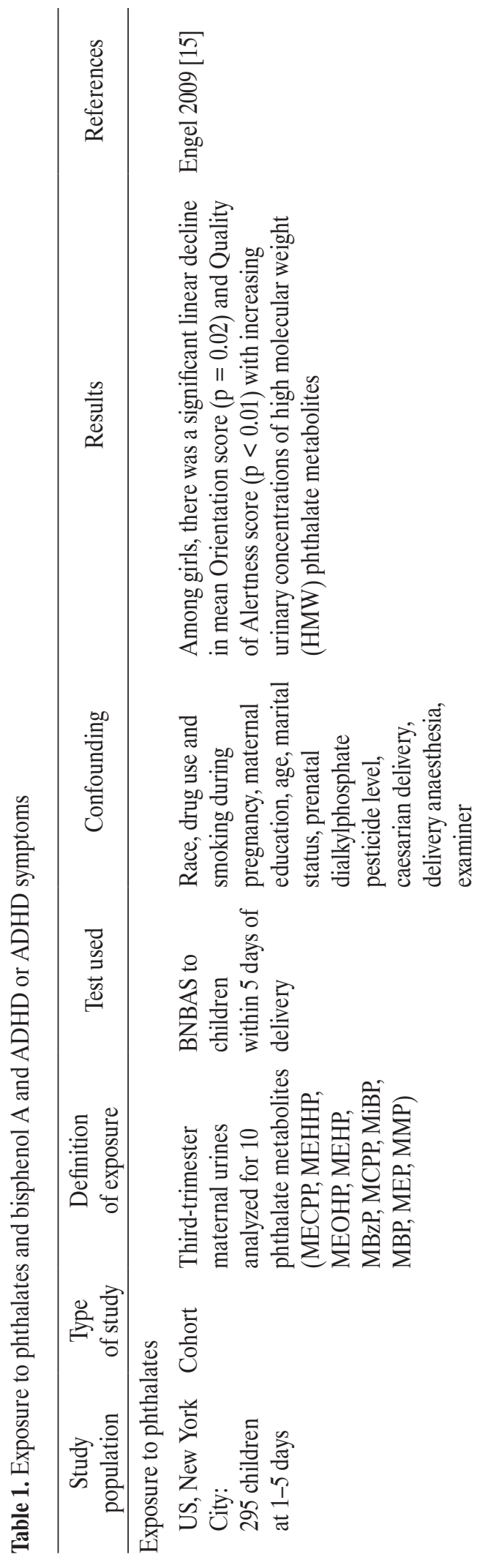

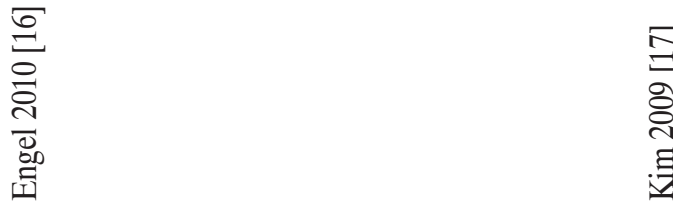
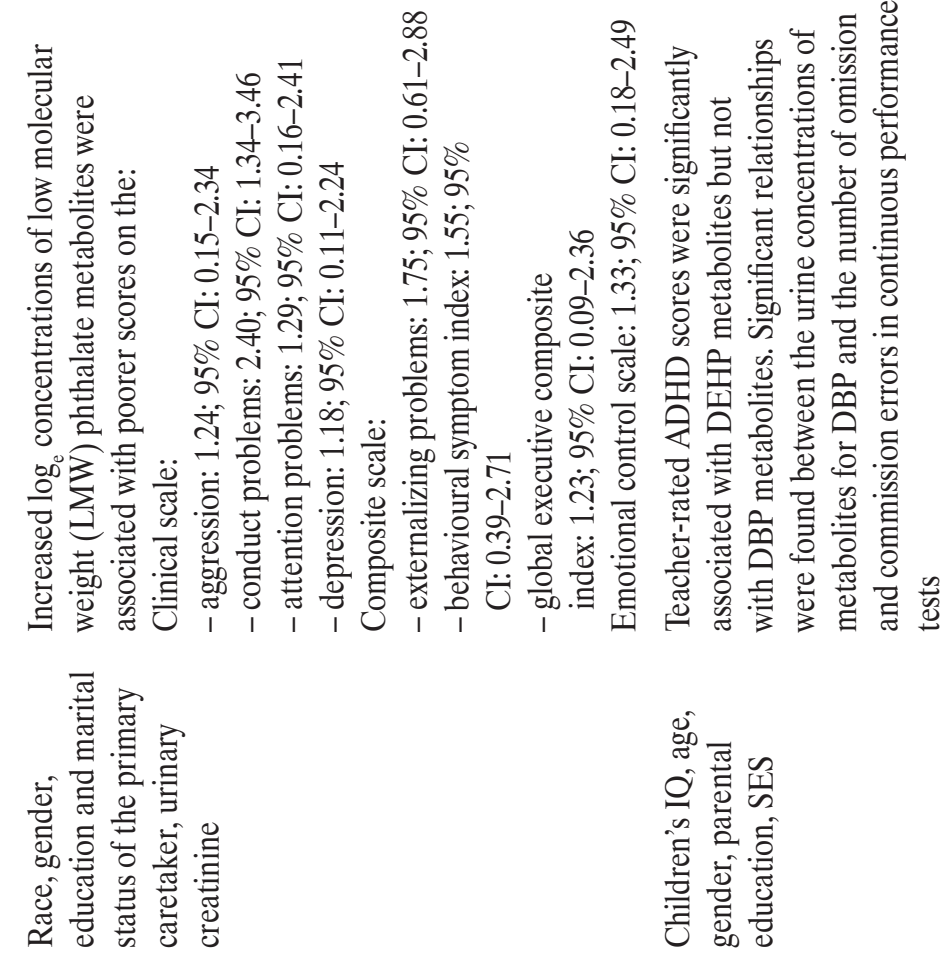

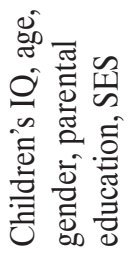

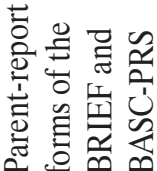
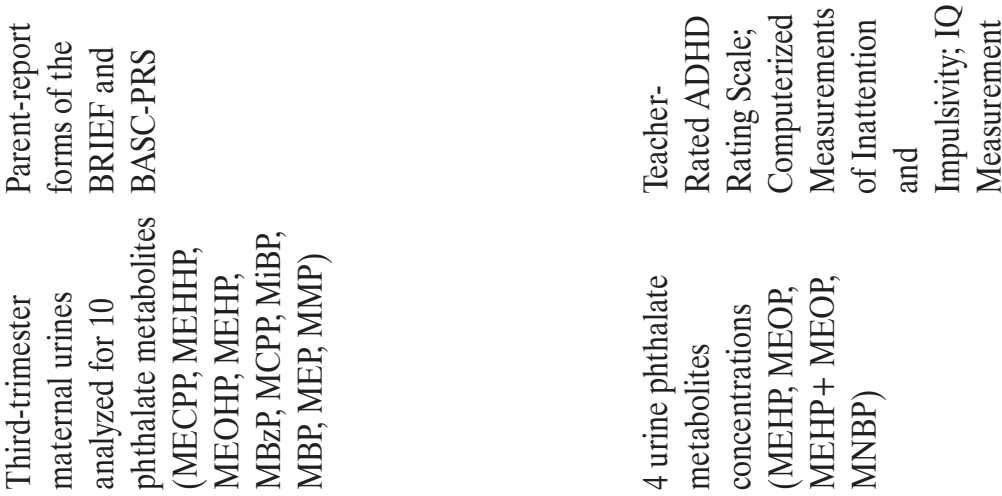

ํㅡㅇ

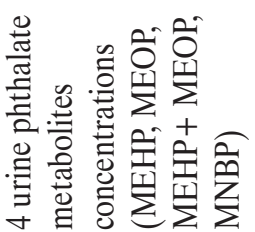

言总密

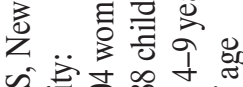

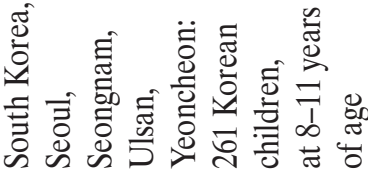



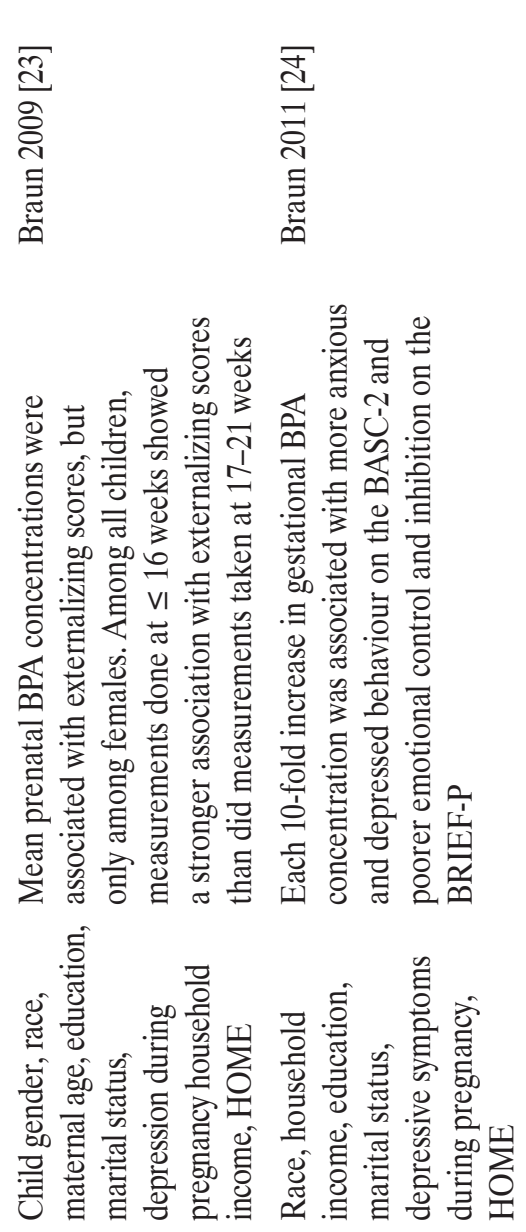

节
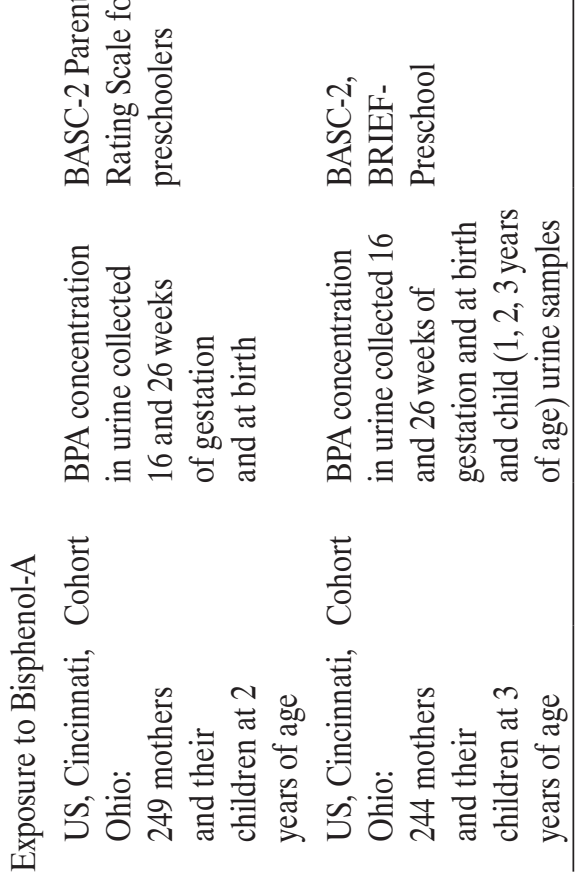

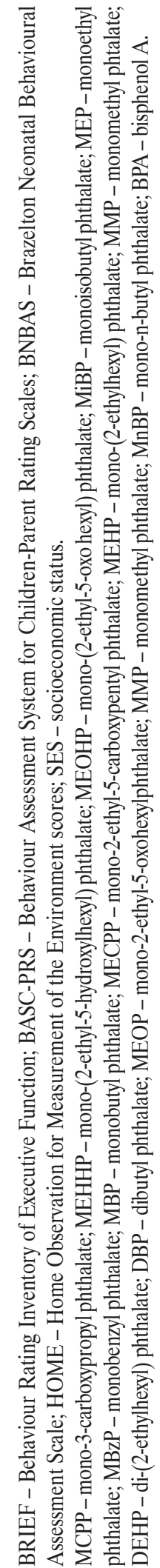

\section{POLYFLUOROALKYL CHEMICALS AND ADHD OR ADHD SYMPTOMS}

Polyfluoroalkyl chemicals (PFCs) have been widely used in consumer products and in industrial applications as surfactants and emulsifiers, food packaging, non-stick pan coatings, fire-fighting foams, paper and textile coatings, and personal care products $[30,31]$. Preliminary data suggest that PFCs may be potential developmental neurotoxicants [32]. Animal studies have indicated that polyfluoroalkyl chemicals may interfere with normal neuromuscular development by inhibiting choline acetyltransferase (ChAT) activity $[33,34]$ or by disturbing lipid metabolism [35].

Hoffman et al. [36] have noticed an association between exposure to PFCs (Perfluorooctane sulfonic acid (PFOS), perfluorooctanoic acid (PFOA), perfluorononanoic acid (PFNA), and perfluorohexane sulfonic acid (PFHxS)) measured in serum samples in children aged 12-15 years in the United States (Boston, Massachusetts) and ADHD diagnosed by a doctor or health care professional. Exposure to PFOS, PFOA, PFHxS was associated with ADHD. On the other hand, Fei et al. [37] did not find adverse effects of prenatal PFC exposure on attention and cognition in children at 6 and 18 months of age (Table 2).

As there are only two studies on exposure to polyfluoroalkyl chemicals and ADHD and ADHD symptoms (attention problems) and their results are inconsistent, it is difficult to reach the right conclusion. The age of individuals in the study populations may explain the difference in the results. Fei et al. [37] assess the exposure to PFCs and ADHD among children around 6 months and 18 months of age whereas Hoffman et al. [36] assess only children 12-15 years of age. Further investigation into the impact of PFC exposure on ADHD and children's neurodevelopment is needed. 


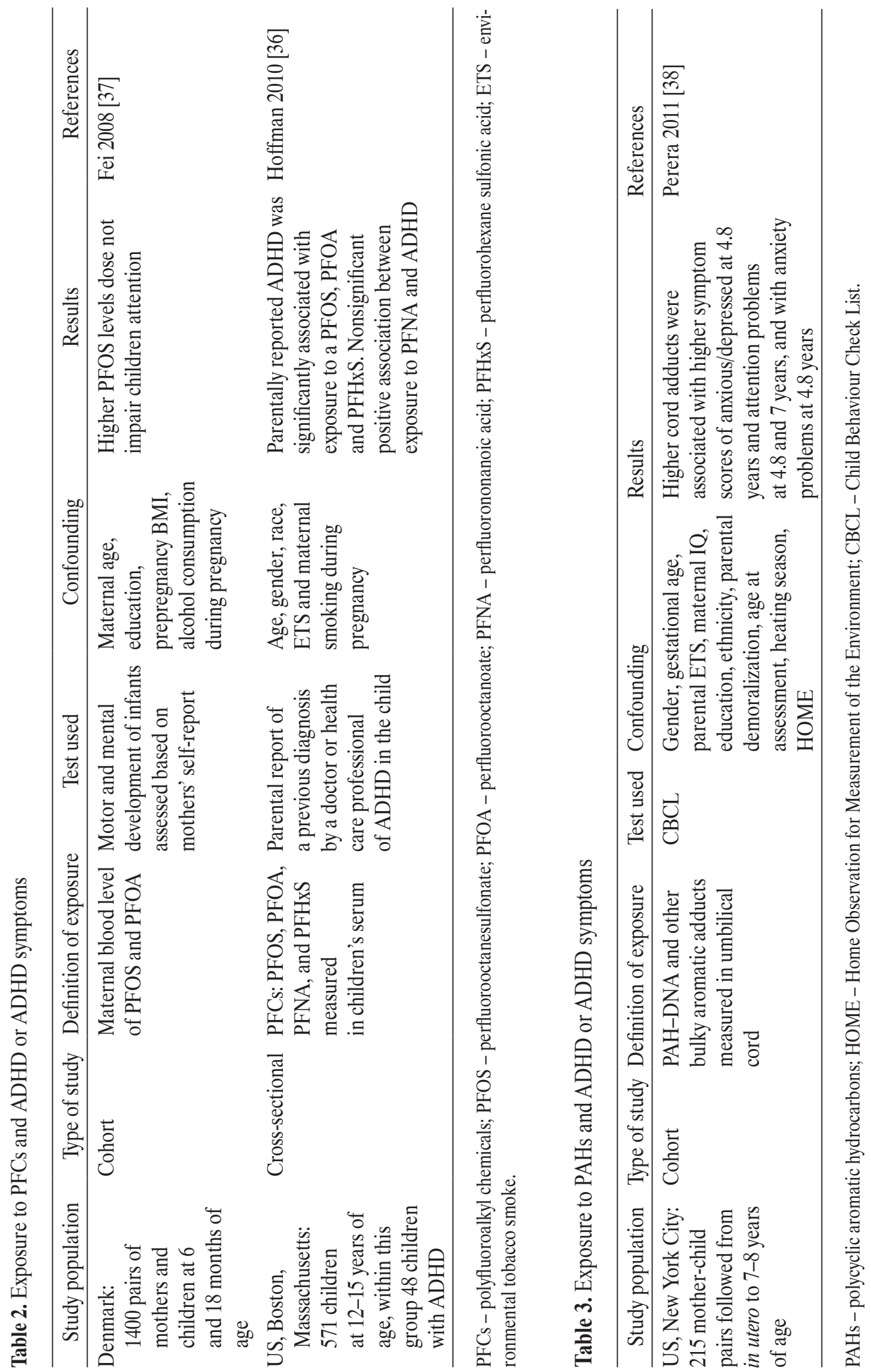




\section{POLYCYCLIC AROMATIC HYDROCARBONS AND ADHD OR ADHD SYMPTOMS}

Polycyclic aromatic hydrocarbons (PAHs) are one of the most widespread organic pollutants. In addition to their presence in fossil fuels they are also formed by incomplete combustion of carbon-containing fuels such as wood, coal, diesel oil, and tobacco [38]. PAHs have been shown to be neurodevelopmental toxicants in experimental studies $[39,40]$. Suggested mechanisms include endocrine disruption [41-43], binding to receptors for placental growth factors resulting in decreased exchange of oxygen and nutrients [44], binding to the human Ah receptor to induce P450 enzymes, DNA damage resulting in activation of apoptotic pathways [45-47], epigenetic effects [48], or oxidative stress due to inhibition of the brain antioxidant scavenging system [49]. Only one study on exposure to polycyclic aromatic hydrocarbons and children's ADHD symptoms was performed [38]. In the birth cohort of children born to non-smoking women, the neurodevelopment was assessed at 4-8 years of age. The PAH-DNA and other bulky aromatic adducts were measured in umbilical cord. Higher cord adducts were associated with higher symptom scores of anxious/depressed at 4.8 years, attention problems at 4.8 and 7 years, and with anxiety problems at 4.8 years as defined in Diagnostic and Statistical Manual of Mental Disorders, 4th edition [38] (Table 3).

\section{TOBACCO SMOKE EXPOSURE AND ADHD OR ADHD SYMPTOMS}

The association between the exposure to tobacco smoke constituents and behaviour problems in children has been studied from the 1970s [50]. Since then, a lot of original papers and several review articles [2,51-55] have been published on the associations of prenatal maternal active or passive smoking and/or postnatal child environmental tobacco smoke exposure with ADHD or ADHD-related disorders in children of different ages.
The physiological explanation for possible adverse effects of intrauterine exposure is that metabolites from tobacco smoke cross the placenta and the foetus is exposed to a $15 \%$ higher nicotine concentration than the smoking mother [56]. The possible mechanism may be modulation of dopaminergic system and increased number of nicotine receptors [57]. Studies on rats demonstrated long-lasting alterations in the structure of hippocampus associated with prenatal exposure to nicotine [57].

Table 4 presents 30 papers, published since 2000, analyzing the association between tobacco smoke exposure and $\mathrm{ADHD}$ or $\mathrm{ADHD}$ symptoms in children, including 7 papers published in 2010 [6,27,58-85]. The strength of association does differ slightly between studies, although generally it appears that the children of smokers are approximately 1.5-3 times more likely to have ADHD or ADHD symptoms than the children of non-smokers. Some studies which analyzed ADHD symptoms based on Diagnostic and Statistical Manual of Mental Disorders (DSM) criteria or DuPaul Rating Scale indicate the statistically significant association with the exposure to tobacco smoke [58,60-64]. In opposite, the results from Hill et al. [65], Nigg et al. [66], Thapar et al. [67] and Lavigne et al. [68] were not statistically significant. Other studies focusing on the specific symptoms such as hyperactivity and/or impulsivity [69-74], aggressive behaviour $[69,72,75,84]$, attention problems $[74,75,77]$ and externalizing problems $[27,75,77-79]$ generally reported consistent positive association.

Some studies analyzing the impact of tobacco smoke exposure on child ADHD-related symptoms have found independent effects of both pre- and postnatal exposure, but most researchers state that the correlation between maternal smoking in pre- and postnatal period is so high that it is difficult to separate the effects. The results for postnatal exposure are less consistent than for prenatal maternal smoking. Since nicotine is transmitted through breast milk, the effect of maternal smoking during the few months after delivery may be more pronounced than 


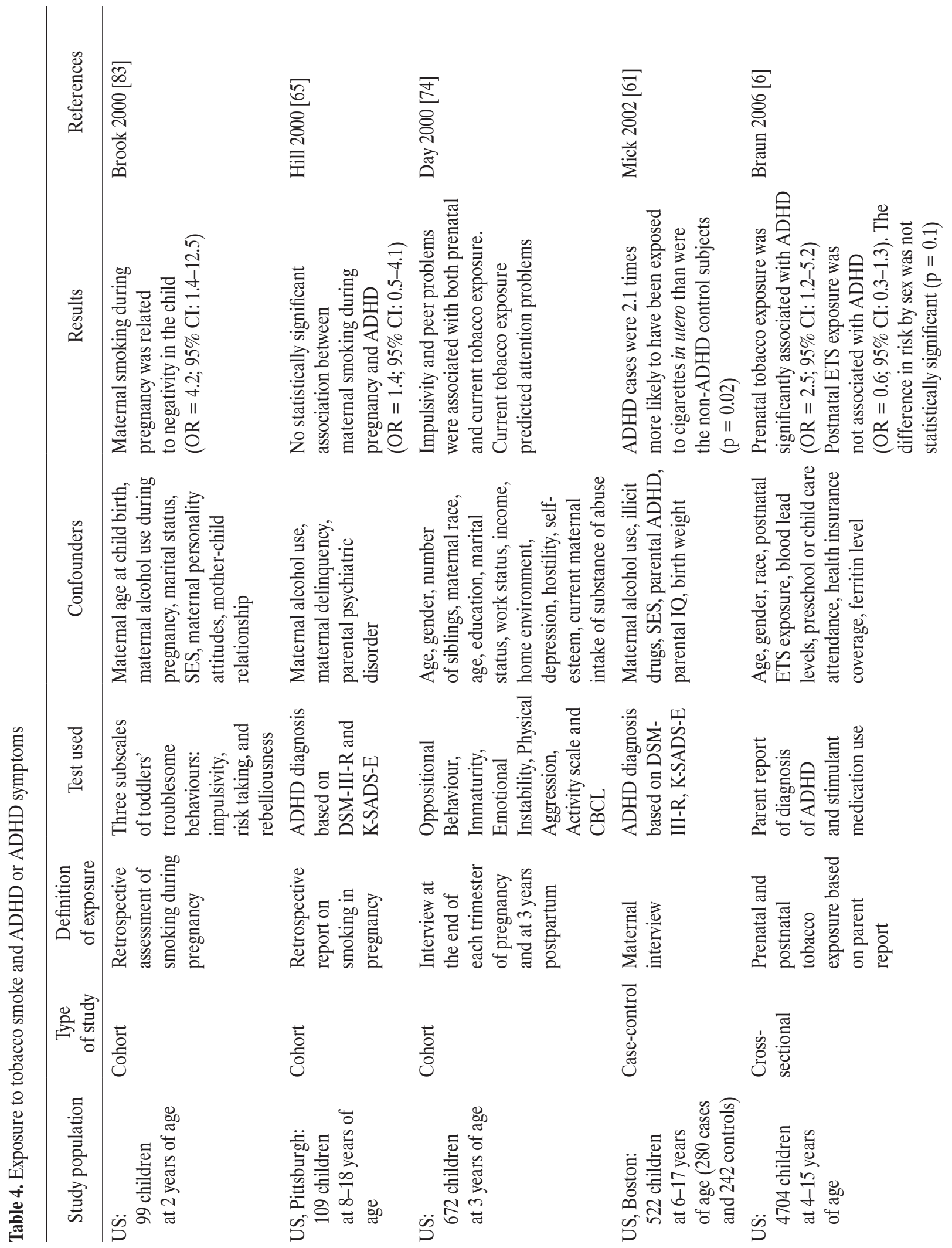




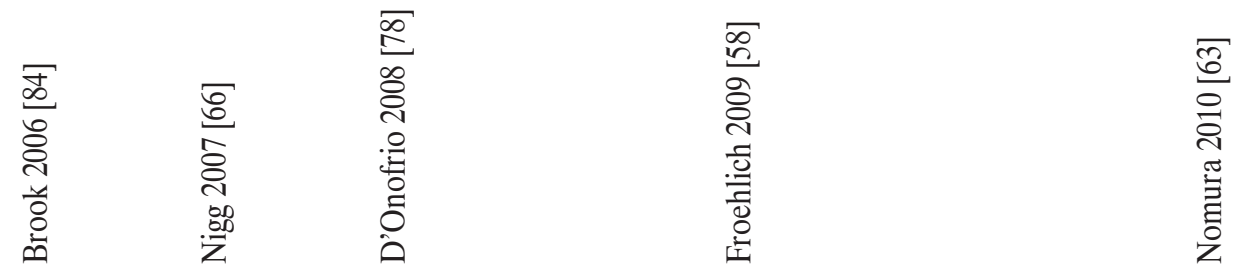
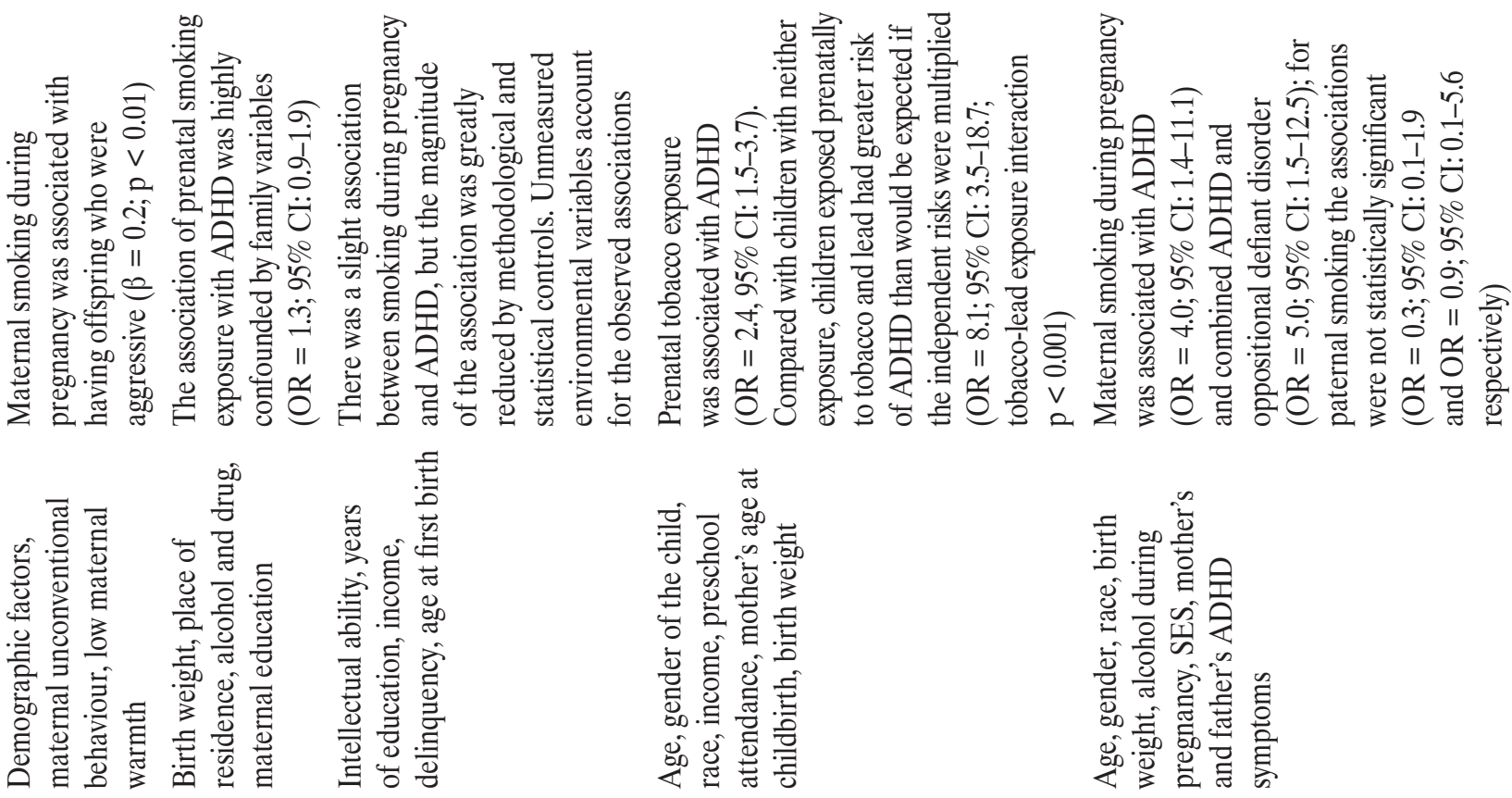

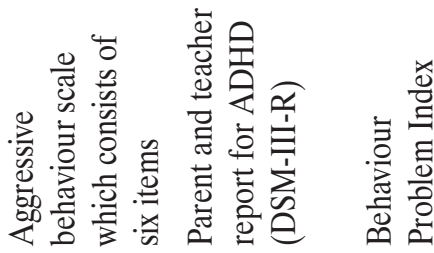

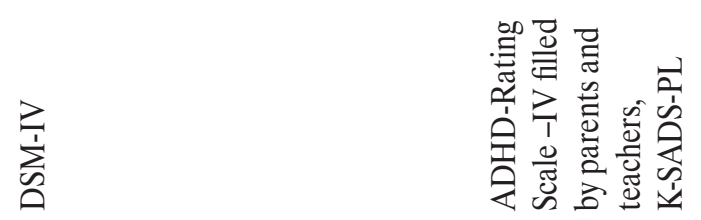

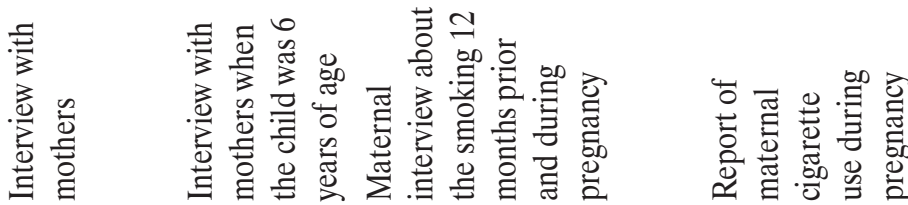

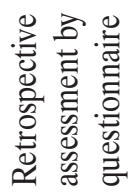

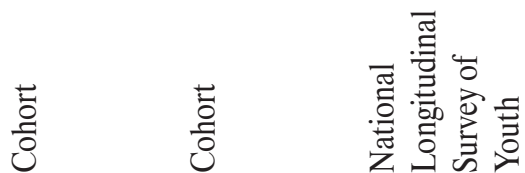

离.

$\frac{5}{0}$
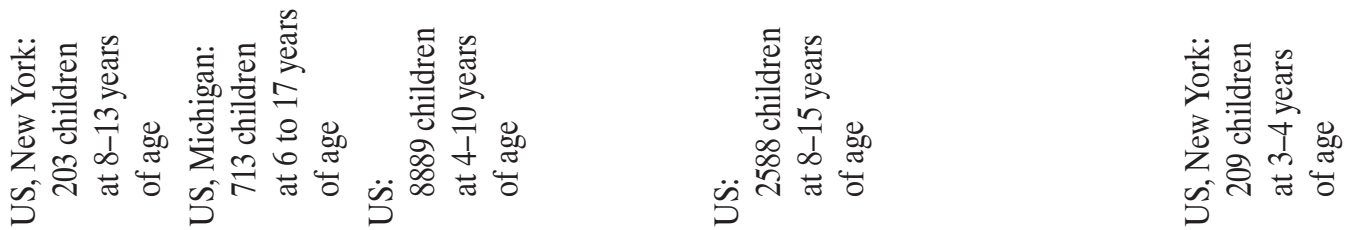


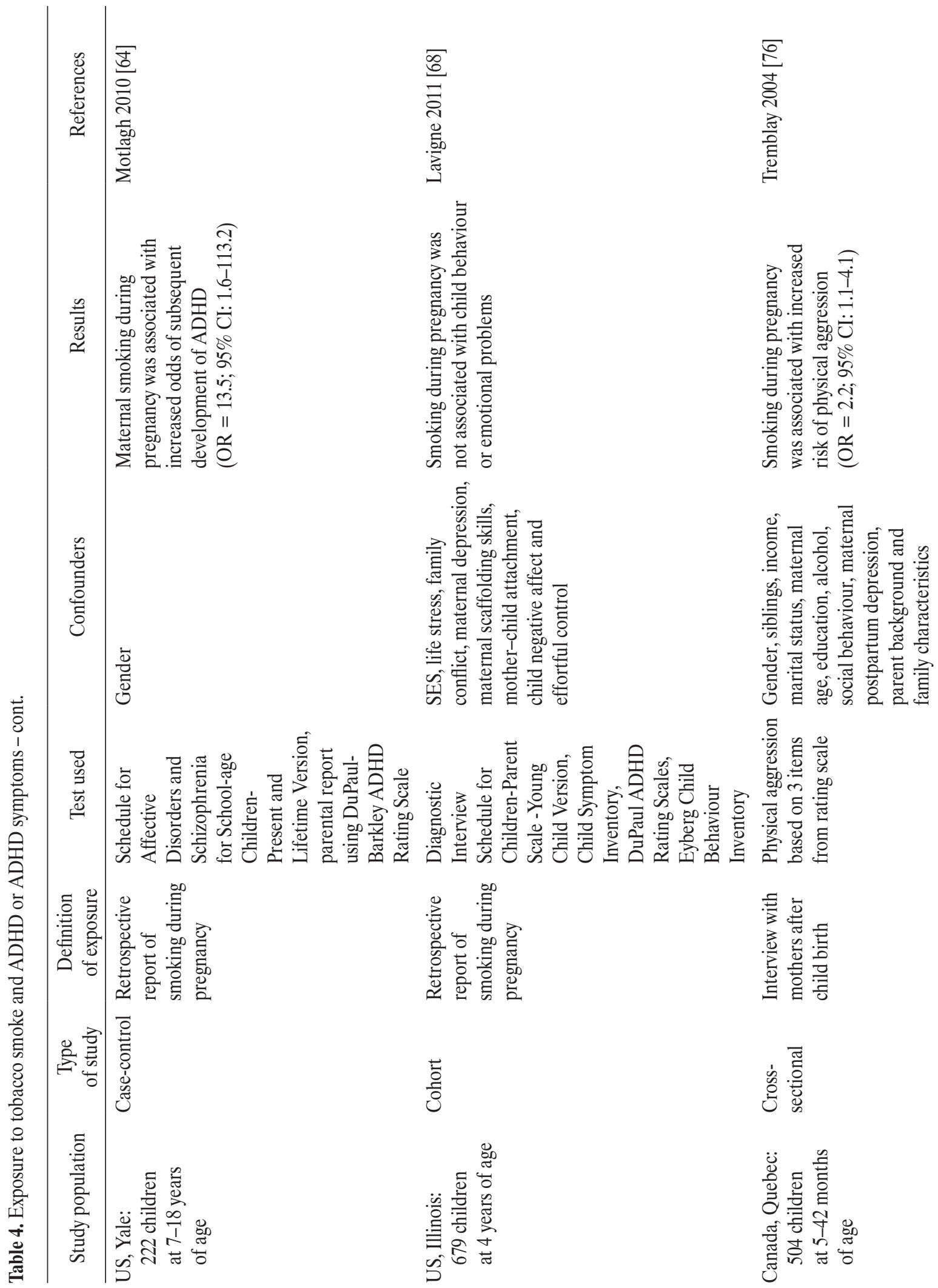



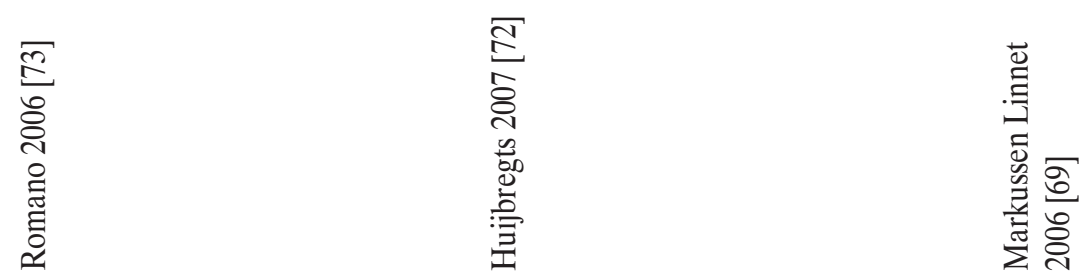

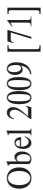
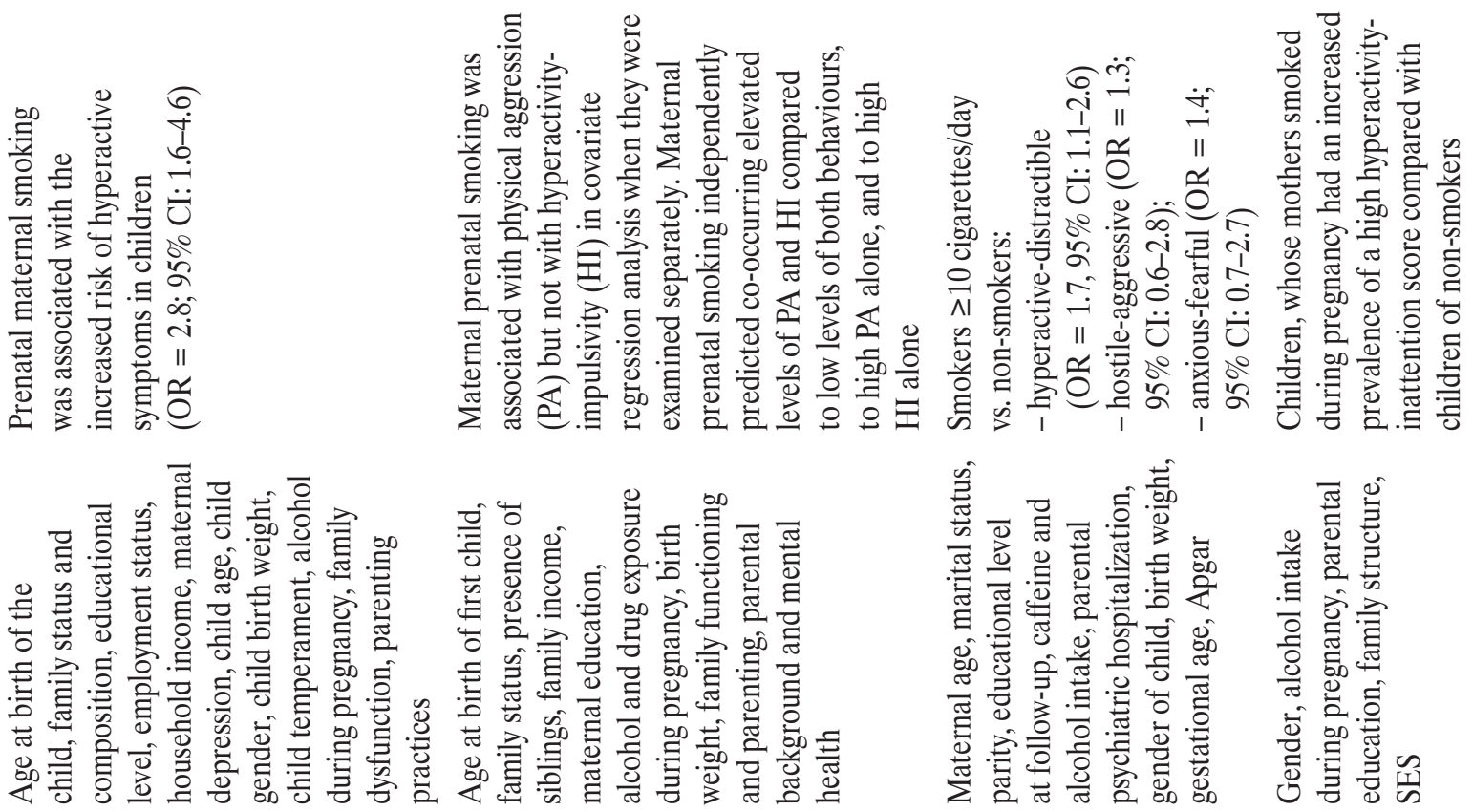

ขึ

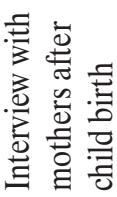

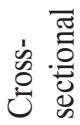

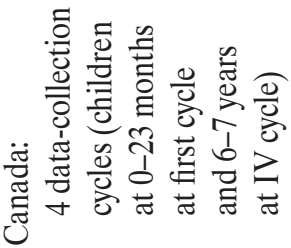

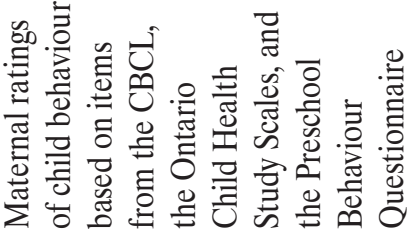

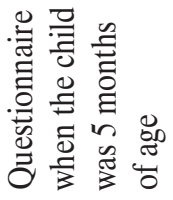

흥

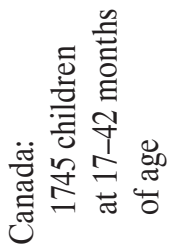

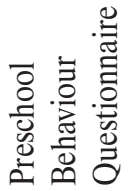
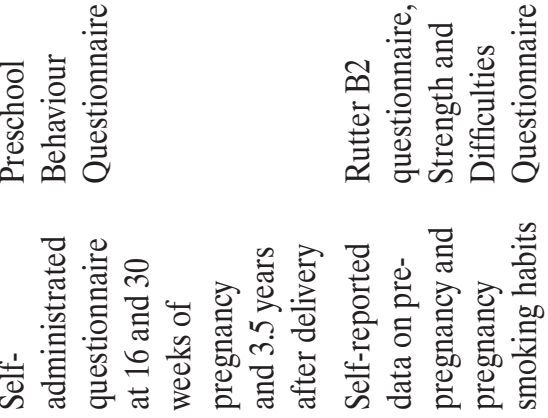

ํㅡㅇ<smiles>[C-]=[Co]</smiles>
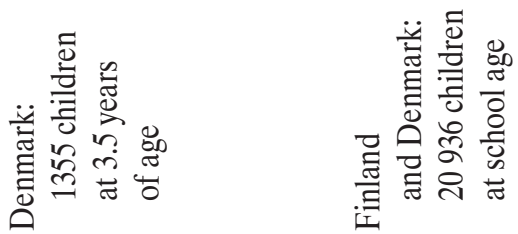


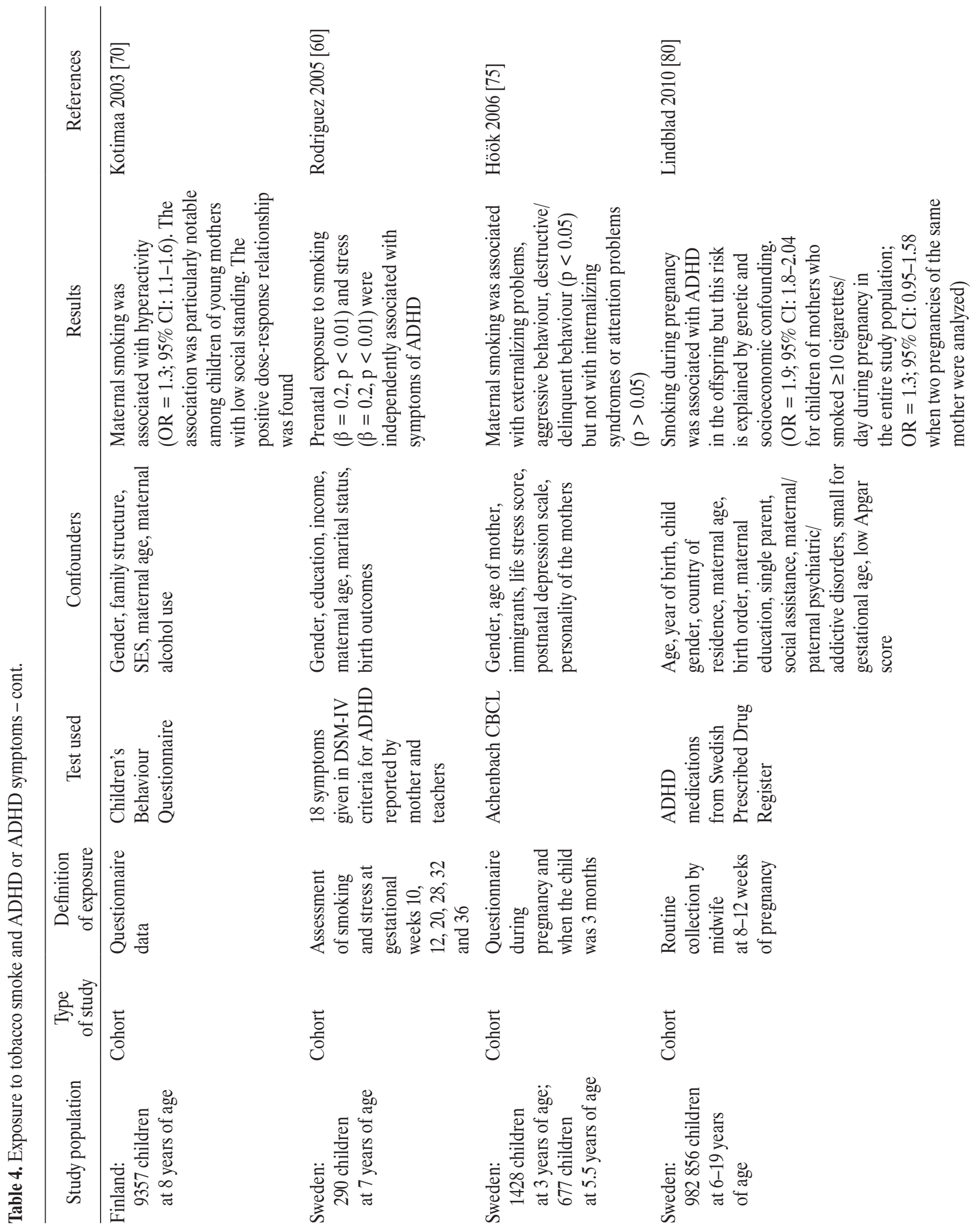




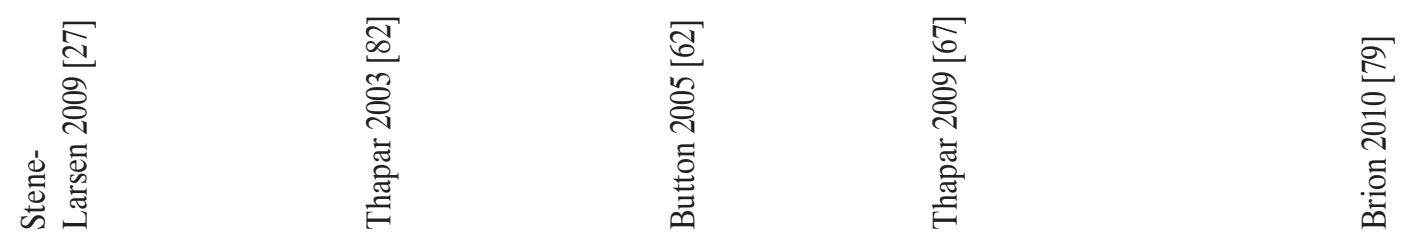

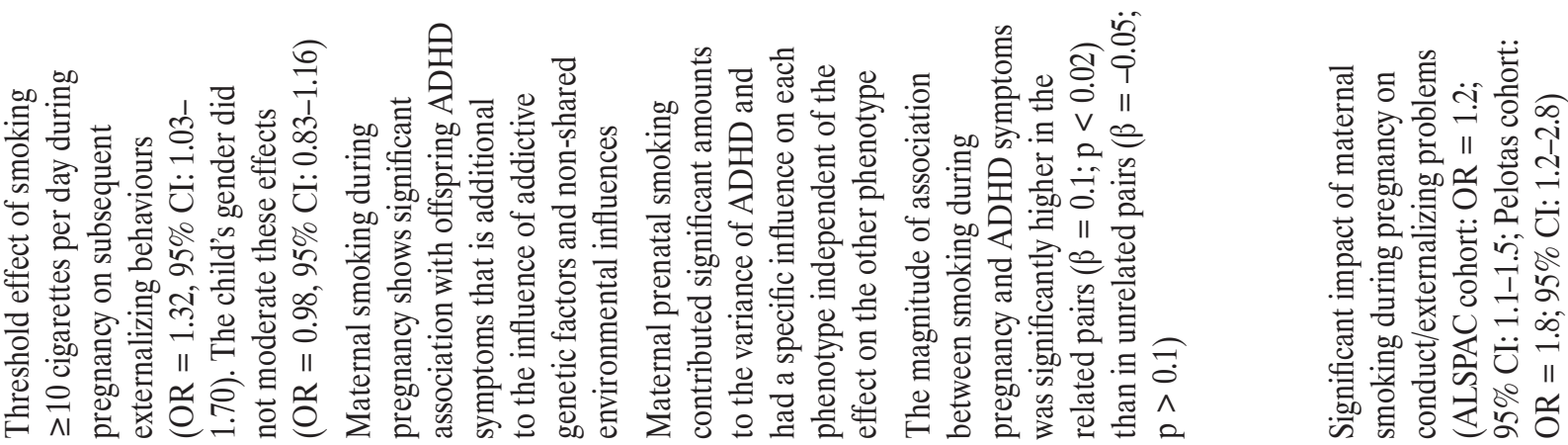

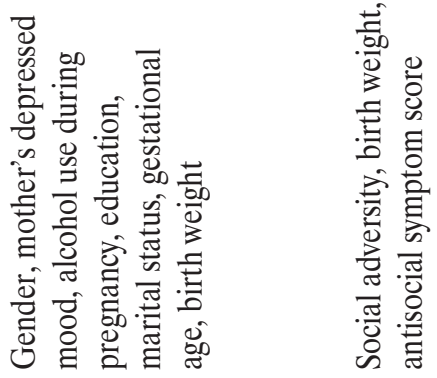

哀

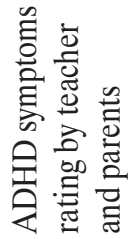

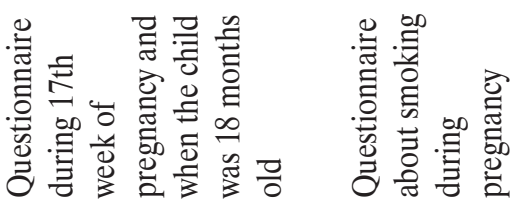

$\frac{5}{0}$

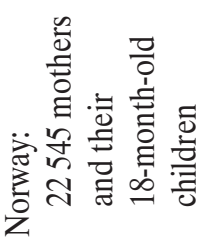

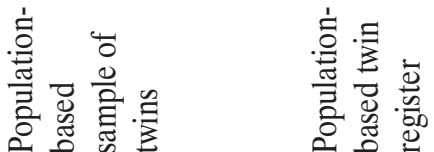

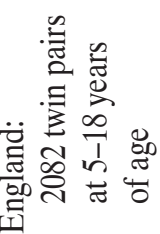

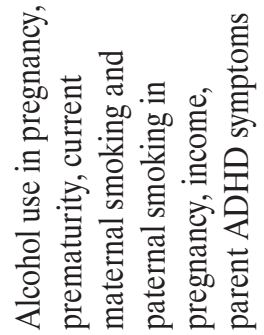

空兽

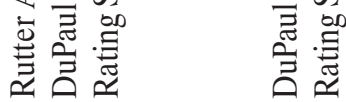
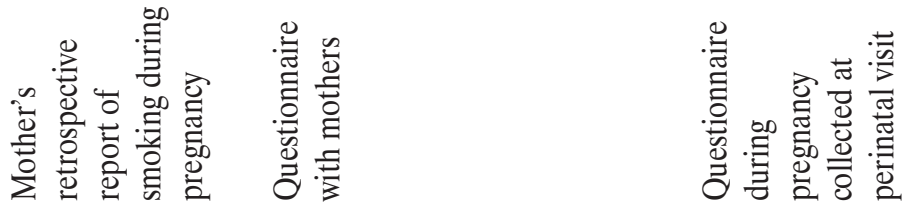

$\frac{5}{0}$

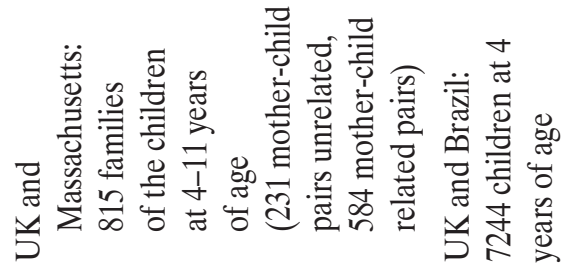




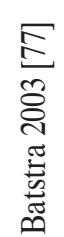

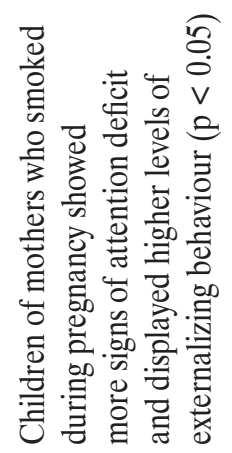

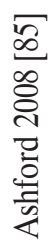

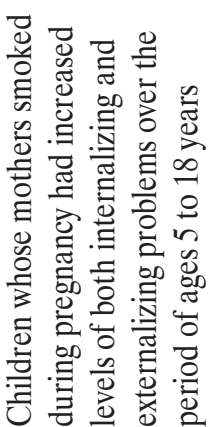

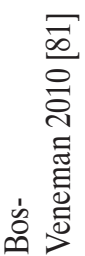
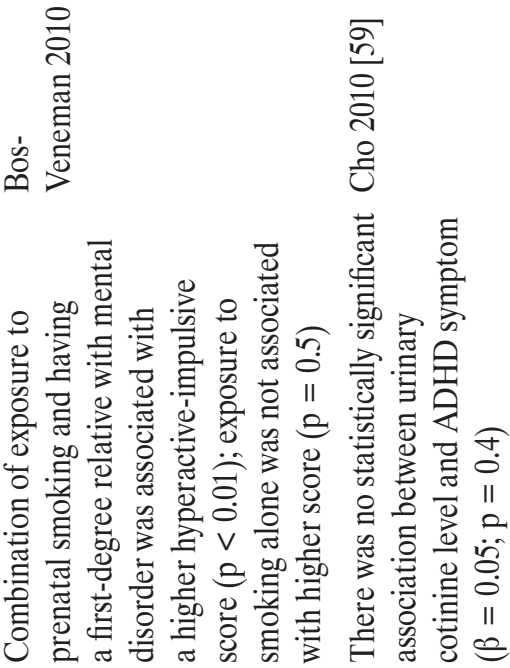
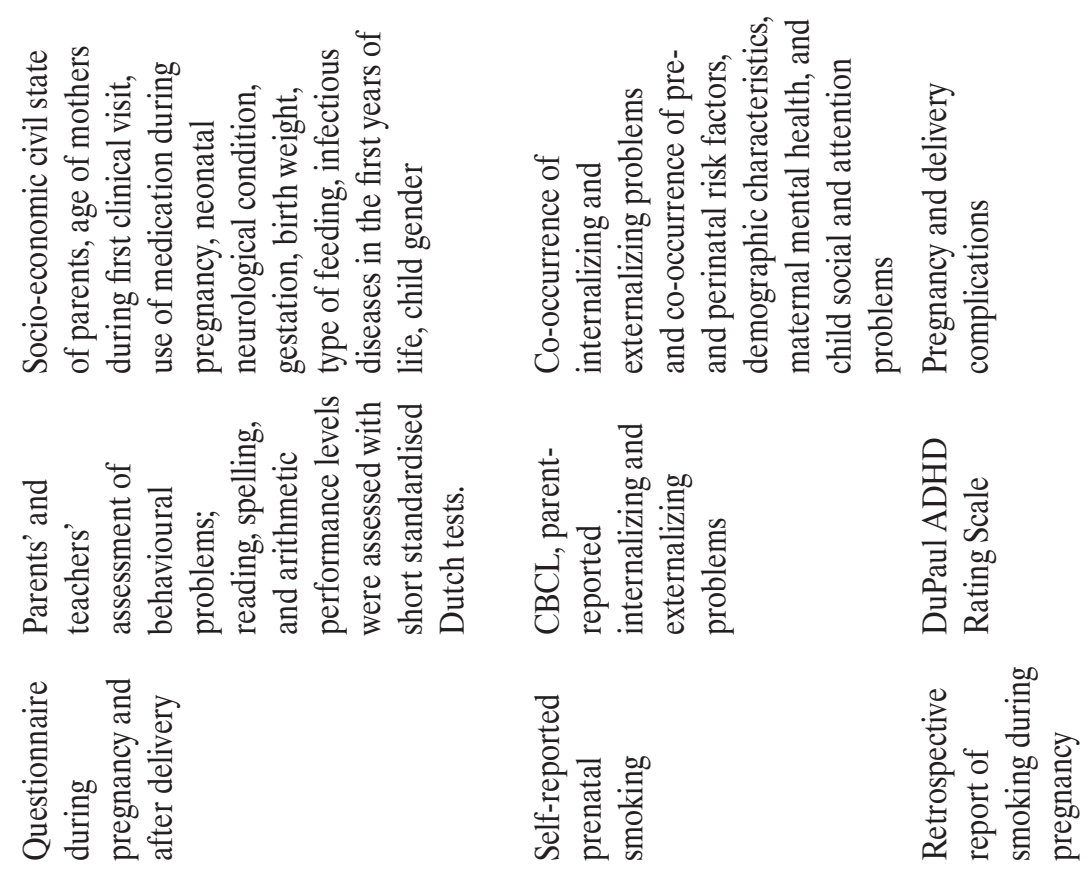

$\frac{5}{0}$

$\frac{5}{0}$

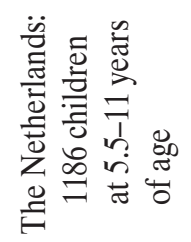

空氮

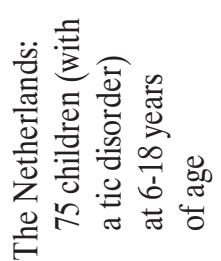

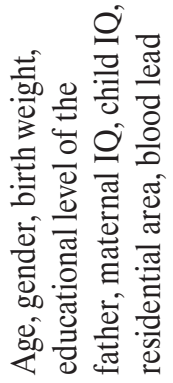
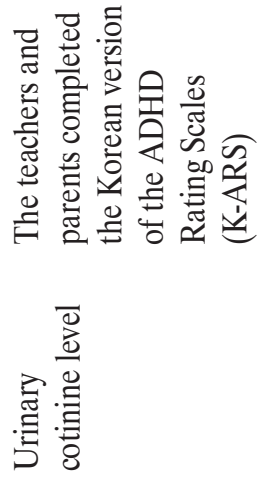

它

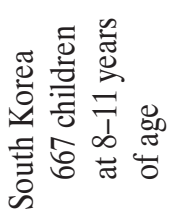


environmental passive smoking during later postnatal periods and during childhood [75]. For example Day et al. [74] indicated that postnatal (not prenatal) exposure predicted attention problems in 3 years old children. On the other hand, Braun et al. [6] did not find statistically significant association between postnatal ETS exposure and ADHD in 4-15 years old children (OR $=0.6$; 95\% CI: 0.3-1.3). Recently, the possibility of genetic factors confounding the study of the effects of smoking during pregnancy on child behaviour outcomes has been raised [86]. Genetic confounding can occur, for example, if mothers with $\mathrm{ADHD}$ who are more likely to smoke also transmit genes that predispose the child to developing ADHD. To address genetic confounds, genetically-sensitive designs are needed to estimate the relative contributions of genetic factors and smoking during pregnancy. The results from D'Onofrio et al. [78], Lindblad and Hjern [80], BosVeneman et al. [81] suggest that the relationship between prenatal tobacco smoke exposure and ADHD may be influenced and/or confounded by familial factors, such as family history of mental disorders. As the example, the analysis based on large Swedish population-based cohort indicated dose-dependent relationship between foetal exposure to tobacco constituents assessed prospectively at prenatal visit and the risk of ADHD medications use in children at $6-19$ years of age $(\mathrm{OR}=1.9 ; 95 \% \mathrm{CI}: 1.8-2.0$ for the children of mothers who smoked $\geq 10$ cigarettes per day during pregnancy in the entire study population) [80]. However, when the authors analyzed multiple births for the same mothers with different smoking status during each pregnancy, there was no longer statistically significant association between such exposure and ADHD (OR $=1.3 ; 95 \%$ CI: 0.95-1.58). Such results are consistent with a paper published by Thapar et al. [82]. The authors used novel, genetically sensitive study design based on offspring conceived with assisted reproductive technologies recruited from fertility clinics (231 unrelated mother-child pairs and 584 mothers related to their children). They concluded that magnitude of the association between smoking during pregnancy and ADHD symptoms was significantly higher in related pairs $(\beta=0.1 ; \mathrm{p}<0.02)$ than in unrelated pairs $(\beta=-0.05 ; p>0.1)$ which confirmed the inherited effect.

In summary, most of published studies indicated statistically significant association between exposure to tobacco smoke constituents and ADHD or ADHD symptoms, although some of the recent studies have indicated that part of this association can result from genetic and/or sociodemographic and lifestyle factors.

\section{ALCOHOL AND ADHD OR ADHD SYMPTOMS}

Maternal alcohol use during pregnancy contributes to a range of effects in exposed children, including hyperactivity and attention problems, learning and memory deficits and problems with social and emotional development [87, 88]. Evidence from animal studies suggests that even a single binge exposure is sufficient to produce neurotoxic effects [89-91]. Ethanol enhances migration of nerve cells, which is hypothesized to be involved in behavioural difficulties in childhood. It also interferes with the production of neuroendocrine hormones, which may perturb brain growth [92].

Six studies examined the association between exposure to alcohol and ADHD and ADHD related symptoms (Table 5). Most of them were performed in the United States: Detroit, Michigan [93,94], Pennsylvania [65], Boston, Massachusetts [61] and one in Canada [73]. A casecontrol study of prenatal exposure to alcohol found that cases of ADHD were 2.5 times more likely to have been exposed to alcohol in utero than were the non-ADHD control subjects; however, when adjusted for confounders, the results were not significant [61]. In addition, adverse effects of prenatal alcohol exposure on aggressive and externalizing behaviour in particular, at age 6-7 years were found evident even at low levels of exposure (one 
alcoholic beverage a week), and showed dose-response effects after control for confounding factors [93]. Also in the study performed by Delaney-Black V et al. [94] prenatal exposure to alcohol was associated with higher total score for externalizing problem (aggressive, delinquent), increased attention problems, and more delinquent behaviours. However, in the study of 150 children/adolescents, prenatal alcohol exposure had no impact on ADHD after adjustment for familial risk of alcoholism, intrauterine exposure to smoking, maternal current alcohol intake, or information on alcohol and parental psychopathology [65]. Also in the study performed in Canada, prenatal maternal drinking was not associated with increased risk of hyperactive symptoms in children [73].

The results of the studies on alcohol exposure and ADHD and ADHD symptoms are inconsistent. Whereas some of them suggest the link between exposure and externalizing and aggressive behaviours [93,94], increased attention problems, more delinquent behaviours [94] and ADHD [116], others [65,73] do not find association between alcohol exposure and hyperactive symptoms in children.

\section{SUMMARY OF THE STUDY RESULTS}

$\mathrm{ADHD}$ is a complex disorder with great heterogeneity in the behavioural symptoms presented and brain functions and structures affected [2]. ADHD heritability, estimated at $60 \%$ to $80 \%$, highlights the considerable role of environmental factors in disorder susceptibility [55,95]. Despite much research has been done on the association between environmental risk factors and ADHD or ADHD symptoms, results are not consistent. Most studies in this field focused on exposure to tobacco smoke and mostly indicated positive association with ADHD and most of its symptoms. On the other hand the impact of phthalates, BPA, PFCs, PAHs and alcohol is less frequently investigated and does not allow for firm conclusion regarding the association with outcomes of interest. Table 6 presents the summary of the impact of different environmental toxicants on ADHD or ADHD symptoms. The increased risk of ADHD was noticed in some studies on the exposure to tobacco constituents $[6,58,60-64,82]$, although a few of them did not give statistically significant results $[65-68,80,81]$. Statistically significant association was noted between ADHD and phthalates [17] and PFCs [36] exposure. Regarding the exposure to alcohol, the results are not consistent. The attention problems were identified among children exposed to PAHs [38] and alcohol [94] and in two studies on tobacco exposure [74,77]. Results of most studies on the impact of exposure to tobacco smoke on impulsivity and hyperactivity were positive [69-71,73,74]. Additionally most studies focusing on the prenatal exposure to tobacco smoke or alcohol indicated higher risk of aggressive behaviour $[72,75,76,84,93,94]$ or externalizing problems $[27,75,77,79,85,93,94]$. Individual difference in vulnerability to chemical contaminants is one potential source of variability in the observed dose-effect relationship. Also genetic polymorphisms can contribute to individual risk from contaminant by affecting toxicokinetic or toxicodynamic variability [96].

Because the studies used different instruments and measured behaviour problems rather than ADHD (some lacking validation), a clear picture does not emerge concerning the link between exposure to environmental factors and symptoms specifically related to ADHD. ADHD terminology has undergone significant changes over the past decades [1]. The ICD-10 and DSM-IV criteria provide very similar list of symptoms but recommend different ways of establishing diagnosis. The ICD-10 requires a minimum number of symptoms in all three dimensions (inattention, overactivity, and impulsivity), additionally it requires that all criteria are met in at least two different situational contexts and includes mood, anxiety, and developmental disorders as exclusion diagnoses. The DSMIV defines only two dimensions (with hyperactivity and 


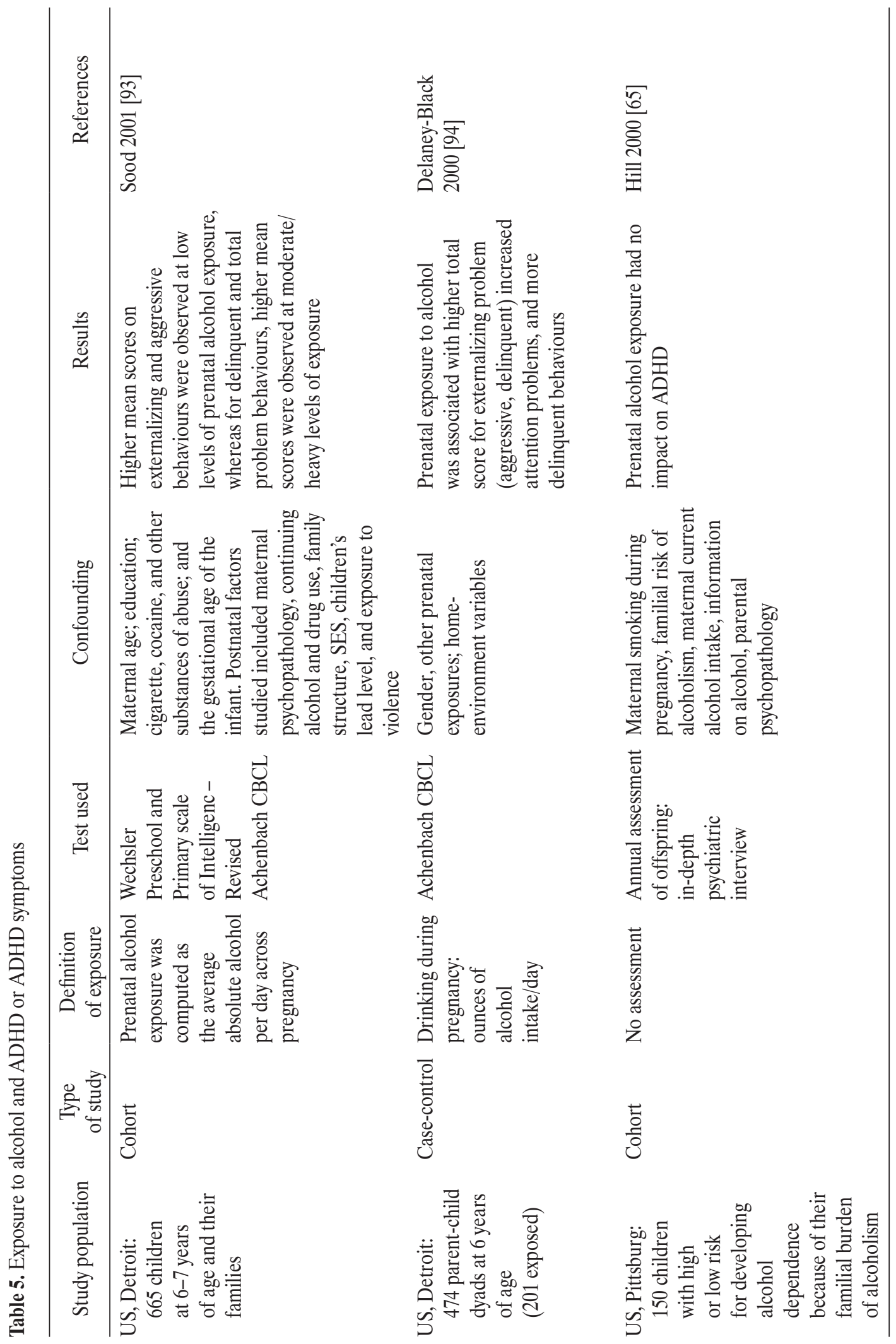




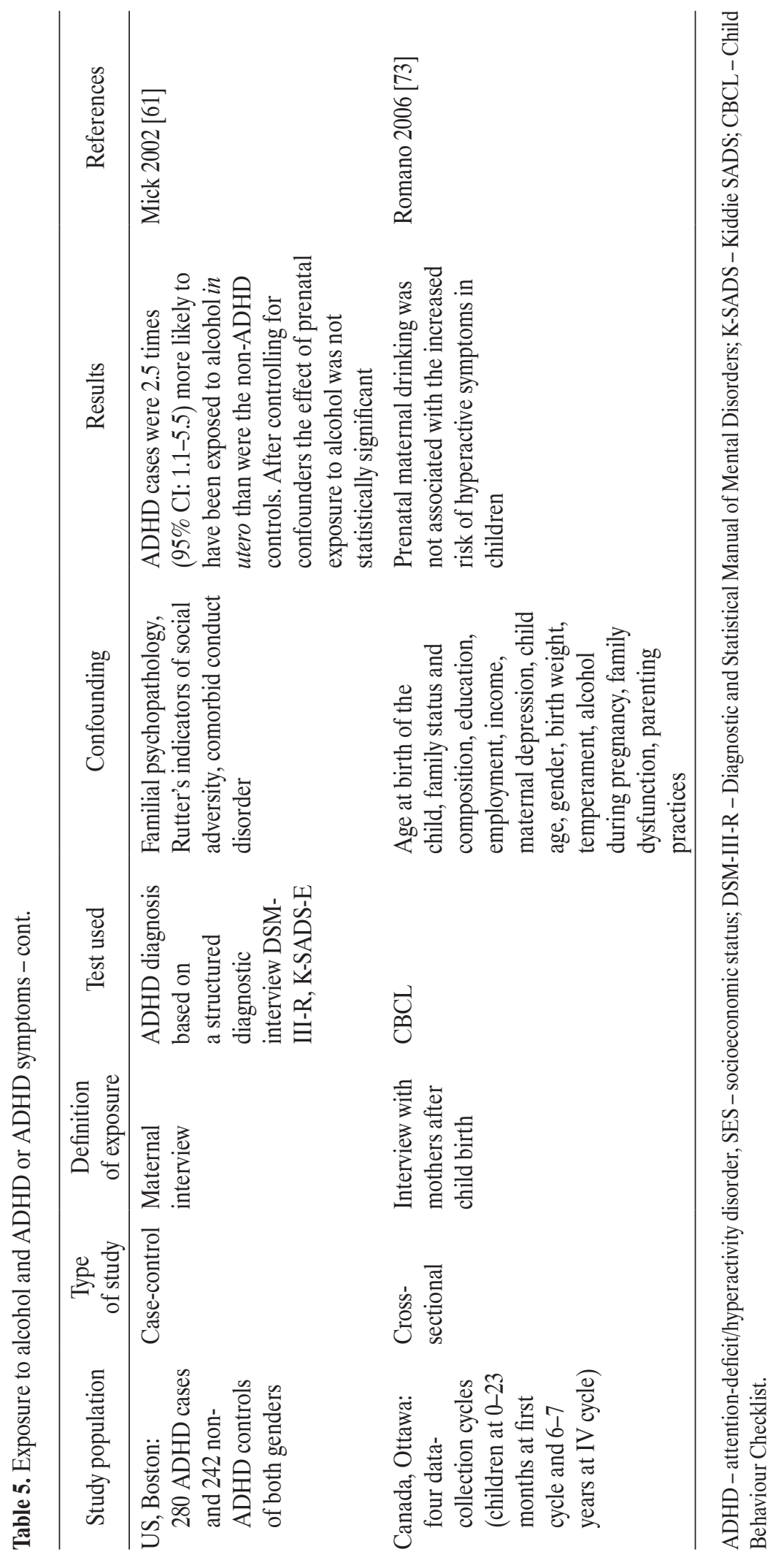




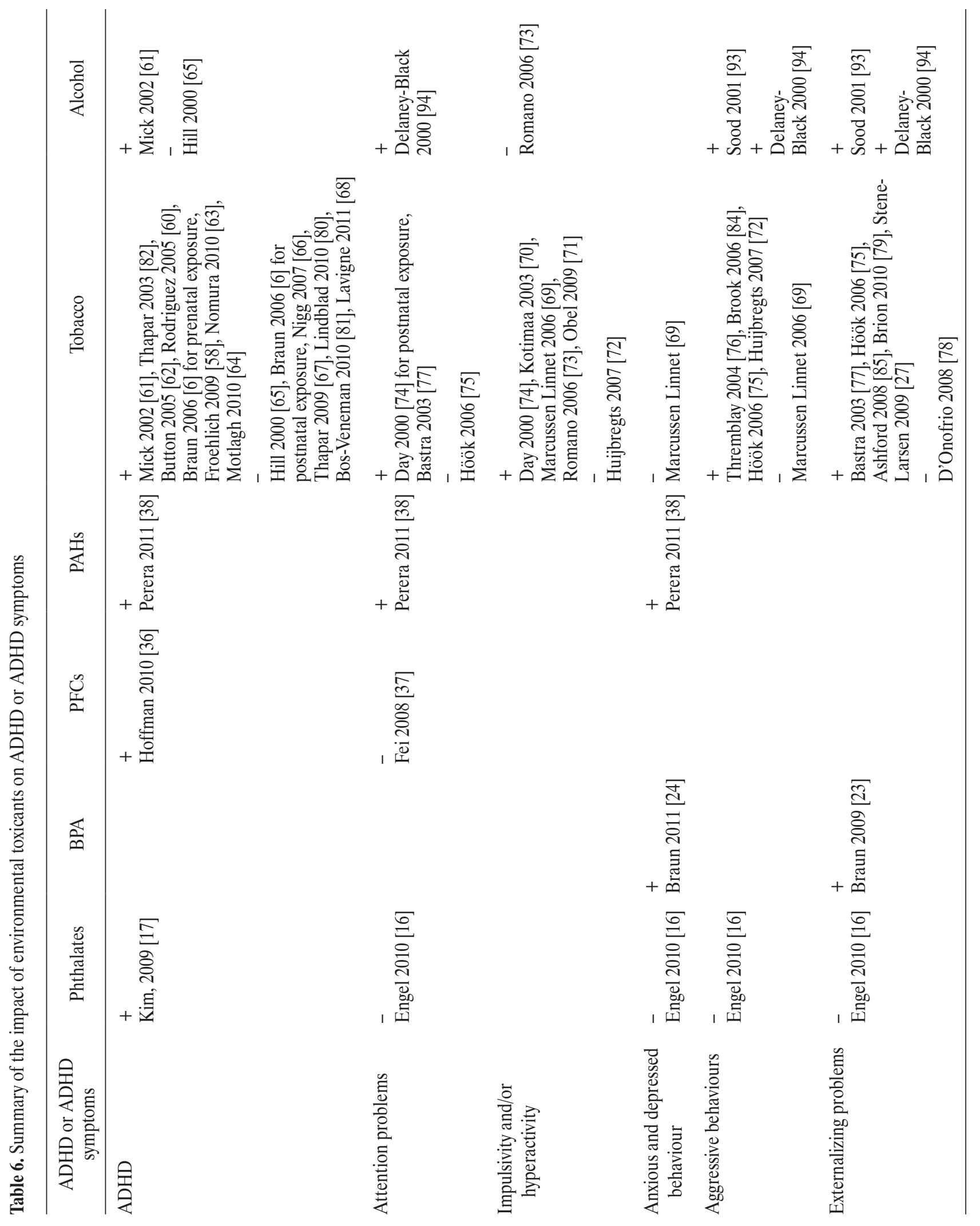




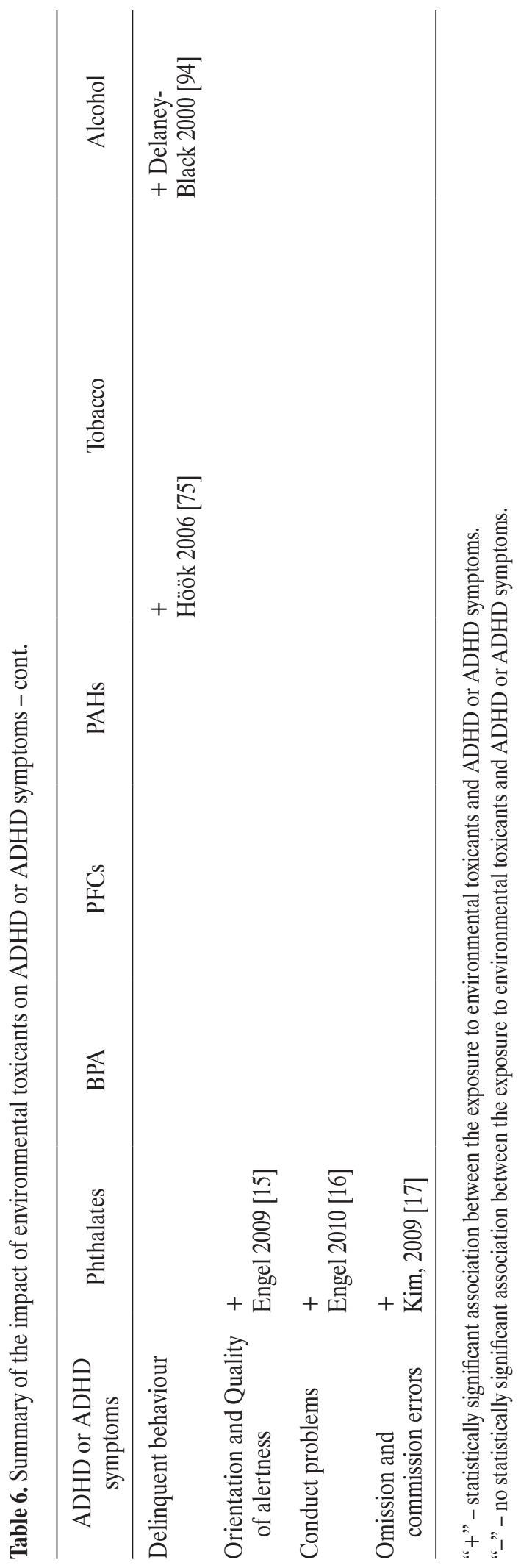

impulsivity symptoms included in the same dimension), and a diagnosis can be made if there is a minimum number of symptoms in only one dimension, it requires the presence of some impairment in more than one setting and the diagnoses may be classified as comorbid conditions [1]. It is important to notice that some studies identified the ADHD or ADHD symptoms in toddlers and preschoolers which may not correlate with later diagnostic status, whereas others identified cases via caregiver report of a prior diagnosis or medical claims. Both situations may result in false positives and negatives [55]. However, previous research indicates that parental reports of ADHD are highly reliable [97].

One key difficulty in identifying the aetiology of the association between variety of environmental risk factors and adverse neurobehavioural outcomes in human studies is the presence of numerous confounders. For appropriate risk assessment it is crucial to have valid assessment of the exposures. In the studies in which exposure status is evaluated from questionnaire data, recall bias can significantly influence the results, especially if evaluated retrospectively. It is also important to note that for some exposures, such as smoking or alcohol consumption, for which detrimental health impacts are well established, the reported exposure levels may be underestimated. Besides the obvious methodological inadequacy of assessing exposure level retrospectively, other limitations include assessing some exposure as dichotomized variable (such as smoking).

Additionally in most studies a single exposure measurement was performed which may not reflect cumulative exposure or exposure at the most developmentally crucial periods [55]. For example mothers who smoke during pregnancy are also more likely to smoke after delivery, so the judgment which exposure period is crucial is difficult. Also most studies continue to focus on one contaminant at a time despite widespread co-exposure to other chemicals which can be potential effect modifiers. Co-exposure could exacerbate, mitigate or mask the toxicity of the exposure 
of interest [96]. Few studies have investigated prevalence of child behaviour problems related to ADHD as the function of prenatal stress [56,60]. Those studies indicated that the role of stress should be taken into account. As the example, smokers tend to smoke more under stress and perceived stress increases the likelihood of continued smoking during pregnancy, so it is reasonable to study smoking and stress together [60]. Increased stress, along with reduced resources for coping with stress, is thought to contribute to the increased risk of a variety of physical health problems among individuals [98,99]. Accumulating evidences suggest that stress exacerbates the toxicity of contaminants such as retinoids, sodium arsenate, cadmium sulphate and ethanol [100]. In addition, given that not all studies adequately assess parental mental health, there are concerns that the relationship between analysed environmental factors and ADHD may be explained by non-measured genetic factors. Potentially confounding effects of genetic influences could not be completely ruled out. Recent studies suggest that genetic influences might not be a confounder but might function to increase the susceptibility of the brain to environmental factors [96]. Gender differences have been recently highlighted in research primarily because boys are overrepresented in clinical samples, which may be due to a more manifest clinical presentation in boys [101] and less impairment is seen in girls [102]. It may be possible that both males and females are affected but in different ways [60,103]. The clinical presentation of attention deficit disorder may be manifested in girls as more inattentive-type problems and in boys as more hyperactive and impulsive behaviours [101,104]. A recent meta-analysis reported that differences in brain morphology between youth with ADHD and controls varied by child sex [105].

Some but not all of the limitations stated above have been addressed in prospective studies more frequently conducted in recent years. Ideal future studies would be based on prospective, longitudinal birth cohorts (with the possibility of combined analysis of data from different cohorts) with the exposure assessment via biomarkers, if applicable, beginning in pregnancy and continuing throughout childhood. A comprehensive assessment of possible risk factors would occur, as would diagnostic evaluation of parent and child mental health and ADHD status, in sample adequately powered to investigate gene-by-exposure, sex-byexposure and exposure-by-exposure interaction.

\section{REFERENCES}

1. Polanczyk G, Lima MS, Horta BL, Biederman J, Rohde LA. The worldwide prevalence of ADHD: A systematic review and metaregression analysis. Am J Psychiatry 2007;164:942-8.

2. Aguiar A, Eubig PA, Schantz SL. Attention deficit/hyperactivity disorder: A focused overview for children's environmental health researchers. Environ Health Perspect 2010;118(12):1646-53.

3. Costello EJ, Mustillo S, Erkanli A, Keeler G, Angold A. Prevalence and development of psychiatric disorders in childhood and adolescence. Arch Gen Psychiatry 2003;60(8):837-44.

4. Lesesne CA, Visser SN, White CP. Attention-deficit/hyperactivity disorder in school-aged children: association with maternal mental health and use of health care resources. Pediatrics 2003;111(5):1232-7.

5. Mannuzza S, Klein RG, Bessler A, Malloy P, LaPadula M. Adult outcome of hyperactive boys. Educational achievement, occupational rank, and psychiatric status. Arch Gen Psychiatry 1993;50(7):565-76.

6. Braun JM, Kahn RS, Froehlich T, Auinger P, Lanphear BP. Exposures to environmental toxicants and attention deficit hyperactivity disorder in U.S. children. Environ Health Perspect 2006;114(12):1904-9.

7. Masuo Y, Morita M, Oka S, Ishido M. Motor hyperactivity caused by a deficit in dopaminergic neurons and the effects of endocrine disruptors: A study inspired by the physiological roles of PACAP in the brain. Regul Pept 2004;15:225-34. 
8. Ghisari M, Bonefeld-Jorgensen EC. Effects of plasticizers and their mixtures on estrogen receptor and thyroid hormone functions. Toxicol Lett 2009;189(1):67-77.

9. Huang PC, Kuo PL, Chou YY, Lin SJ, Lee CC. Association between prenatal exposure to phthalates and the health of newborns. Environ Int 2009;35(1):14-20.

10. Xu Y, Agrawal S, Cook TJ, Knipp GT. Di-(2-ethylhexyl)phthalate affects lipid profiling in fetal rat brain upon maternal exposure. Arch Toxicol 2007;81(1):57-62.

11. Tanida T, Warita K, Ishihara K, Fukui S, Mitsuhashi T, Sugawara T, et al. Fetal and neonatal exposure to three typical environmental chemicals with different mechanisms of action: mixed exposure to phenol, phthalate, and dioxin cancels the effects of sole exposure on mouse midbrain dopaminergic nuclei. Toxicol Lett 2009;189(1):40-7.

12. Ishido M, Masuo Y, Kunimoto M, Oka S, Morita M. Bisphenol A causes hyperactivity in the rat concomitantly with impairment of tyrosine hydroxylase immunoreactivity. J Neurosci Res 2004;76(3):423-33.

13. Borch J, Metzdorff SB, Vinggaard AM, Brokken L, Dalgaard M. Mechanisms underlying the anti-androgenic effects of diethylhexyl phthalate in fetal rat testis. Toxicology 2006;223(1-2):144-55.

14. Ishido M, Masuo Y, Sayato-Suzuki J, Oka S, Niki E, Morita M. Dicyclohexylphthalate causes hyperactivity in the rat concomitantly with impairment of tyrosine hydroxylase immunoreactivity. J Neurochem 2004;91(1):69-76.

15. Engel SM, Zhu C, Berkowitz GS, Calafat AM, Silva MJ, Miodovnik A, Wolff MS. Prenatal phthalate exposure and performance on Neonatal Behavioral Assessment Scale in multiethnic birth cohort. Neurotoxicology 2009;30:522-8.

16. Engel SM, Miodovnik A, Canfield RL, Zhu C, Silva MJ, Calafat AM, et al. Prenatal phthalate exposure is associated with childhood behavior and executive functioning. Environ Health Perspect 2010;118(4):565-71.

17. Kim BN, Cho SC, Kim Y, Shin MS, Yoo HJ, Kim JW, et al. Phthalates exposure and attention-deficit/hyperactivity disorder in school-age children. Biol Psychiatry 2009;66(10):958-63.
18. Welshons WV, Nagel SC, vom Saal FS. Large effects from small exposures, part III: endocrine mechanisms mediating effects of bisphenol A at levels of human exposure. Endocrinology 2006;147(6 Suppl):56-69.

19. vom Saal FS, Akingbemi BT, Belcher SM, Birnbaum LS, Crain DA, Eriksen M, et al. Chapel Hill bisphenol A expert panel consensus statement: integration of mechanisms, effects in animals and potential to impact human health at current levels of exposure. Reprod Toxicol 2007;24(2):131-8.

20. Palanza P, Gioiosa L, vom Saal FS, Parmigiani S. Effects of developmental exposure to bisphenol $A$ on brain and behavior in mice. Environ Res 2008;108(2):150-7.

21. Tian YH, Baek JH, Lee SY, Jang CG. Prenatal and postnatal exposure to bisphenol $A$ induces anxiolytic behaviors and $\operatorname{cog}$ nitive deficits in mice. Synapse 2010;64(6):432-9.

22. Palanza P, Morellini F, Parmigiani S, vom Saal FS. Prenatal exposure to endocrine disrupting chemicals: effects on behavioral development. Neurosci Biobehav Rev 1999;23(7): 1011-27.

23. Braun JM, Yolton K, Dietrich KN, Horunung R, Ye X, Calafat AM, et al. Prenatal bisphenol A exposure and early childhood behavior. Environ Health Perspect 2009;117(12): 1945-52.

24. Braun JM, Kalkbrenner AM, Calafat AM, Yolton K, Ye X, Dietrich KN, et al. Impact of Early-Life Bisphenol A exposure on behavior and executive function in children. Pediatrics 2011;128(5):873-82.

25. Longnecker MP. Human data on Bisphenol $A$ and neurodevelopment. Environ Health Perspect 2009;117(12):531-2.

26. Hölling H, Kurth BM, Rothenberger A, Becker A, Schlack R. Assessing psychopathological problems of children and adolescents from 3 to 17 years in a nationwide representative sample: results of the German health interview and examination survey for children and adolescents (KiGGS). Eur Child Adolesc Psychiatry 2008;17(Suppl 1):34-41.

27. Stene-Larsen K, Borge AI, Vollrath ME. Maternal smoking in pregnancy and externalizing behavior in 18-month-old 
children: results from a population-based prospective study. J Am Acad Child Adolesc Psychiatry 2009;48:283-9.

28. Ryan BC, Vandenbergh JG. Developmental exposure to environmental estrogens alters anxiety and spatial memory in female mice. Horm Behav 2006;50:85-93.

29. Kuiper GG, Lemmen JG, Carlsson B, Corton JC, Safe SH, van der Saag PT, et al. Interaction of estrogenic chemicals and phytoestrogens with estrogen receptor $\beta$. Endocrinology 1998;139:4252-63.

30. Calafat AM, Wong LY, Kuklenyik Z, Reidy JA, Needham LL. Polyfluoroalkyl chemicals in the U.S. population: data from the National Health and Nutrition Examination Survey (NHANES) 2003-2004 and comparisons with NHANES 1999-2000. Environ Health Perspect 2007;115:1596-602.

31. Renner R. Growing concern over perfluorinated chemicals. Environ Sci Technol 2001;35(7):154-60.

32. Slotkin TA, MacKillop EA, Melnick RL, Thayer KA, Seidler FJ. Developmental neurotoxicity of perfluorinated chemicals modelled in vitro. Environ Health Perspect 2008;116: 716-22.

33. Johansson N, Fredriksson A, Eriksson P. Neonatal exposure to perfluorooctane sulfonate (PFOS) and perfluorooctanoic acid (PFOA) causes neurobehavioural defects in adult mice. Neurotoxicology 2008;29(1):160-9.

34. Lau C, Thibodeaux JR, Hanson RG, Rogers JM, Grey BE, Stanton ME, et al. Exposure to perfluorooctane sulfonate during pregnancy in rat and mouse. II: Postnatal evaluation. Toxicol Sci 2003;74(2):382-92.

35. Fuentes S, Vicens P, Colomina MT, Domingo JL. Behavioral effects in adult mice exposed to perfluorooctane sulfonate (PFOS). Toxicology 2007;242:123-9

36. Hoffman K, Webster TF, Weisskopf MG, Weinberg J, Vieira MV. Exposure to polyfluoroalkyl chemicals and attention deficit/hyperactivity disorder in U.S. children 12-15 years of age. Environ Health Perspect 2010;118(12):1762-7.

37. Fei C, McLaughlin JK, Lipworth L, Olsen J. Prenatal exposure to perfluorooctanoate (PFOA) and perfluorooctanesulfonate (PFOS) and maternally reported developmental milestones in infancy. Environ Health Perspect 2008;116(10):1391-5.
38. Perera FP, Wang S, Vishnevetsky J, Zhang B, Cole KJ, Tang D, et al. Polycyclic Aromatic Hydrocarbons-Aromatic DNA Adducts in Cord Blood and Behavior Scores in New York City Children. Environ Health Perspect 2011;119(8):1176-81.

39. Saunders CR, Das SK, Ramesh A, Shockley DC, Mukherjee S. Benzo(a)pyrene-induced acute neurotoxicity in the F-344 rat: role of oxidative stress. J Appl Toxicol 2006;26:427-38.

40. Šrám RJ, Binkova B. Molecular epidemiology studies on occupational and environmental exposure to mutagens and carcinogens, 1997-1999. Environ Health Perspect 2000;108:57-70.

41. Archibong AE, Inyang F, Ramesh A, Greenwood M, Nayyar T, Kopsombut P, et al. Alteration of pregnancy related hormones and fetal survival in F-344 rats exposed by inhalation to benzo(a)pyrene. Reprod Toxicol 2002;16:801-8.

42. Bui QQ, Tran MB, West WL. A comparative study of the reproductive effects of methadone and benzo(a)pyrene in the pregnant and pseudopregnant rat. Toxicol 1986;42(2-3): 195-204.

43. Takeda K, Tsukue N, Yoshida S. Endocrine-disrupting activity of chemicals in diesel exhaust and diesel exhaust particles. Environ Sci 2004;11:33-45.

44. Dejmek J, Solansky I, Beneš I, Lenícek J, Šrám RJ. The impact of polycyclic aromatic hydrocarbons and fine particles on pregnancy outcome. Environ Health Perspect 2000;108: 1159-64.

45. Meyn MS. Ataxia-telangiectasia and cellular responses to DNA damage. Cancer Res 1995;55:5991-6001.

46. Nicol CJ, Harrison ML, Laposa RR, Gimelshtein IL, Wells PG. A teratologic suppressor role for p53 in benzo[a]pyrenetreated transgenic p53-deficient mice. Nat Genet 1995;10: 181-7.

47. Wood KA, Youle RJ. The role of free radicals and p53 in neuron apoptosis in vivo. J Neuroscience 1995;15:5851-7.

48. Wilson VL, Jones PA. Inhibition of DNA methylation by chemical carcinogens in vitro. Cell 1983;32(1):239-46. 
49. Lundqvist C, Zuurbier M, Leijs M, Johansson C, Ceccatelli S, Saunders M, et al. The effects of PCBs and dioxins on child health. Acta Paediatr 2006;453(Suppl 95):55-64.

50. Denson R, Nanson JL, McWatters MA. Hyperkinesis and maternal smoking. Can Psychiatr Assoc J 1975;20:183-7.

51. Linnet KM, Dalsgaard S, Obel C, Wisborg K, Henriksen TB, Rodriguez A, et al. Maternal lifestyle factors in pregnancy risk of attention deficit hyperactivity disorder and associated behaviors: review of the current evidence. Am J Psychiatry 2003;160(6):1028-40.

52. Banerjee TD, Middleton F, Faraone SV. Environmental risk factors for attention-deficit hyperactivity disorder. Acta Paediatr 2007;96(9):1269-74.

53. Nigg J, Nikolas M, Burt SA. Measured gene-by-environment interaction in relation to attention-deficit/hyperactivity disorder. J Amer Acad Child Adolesc Psychiatry 2010; 49: 863-73.

54. Button TM, Maughan B, McGuffin P. The relationship of maternal smoking to psychological problems in the offspring. Early Hum Dev 2007;83(11):727-32.

55. Froehlich TE, Anixt JS, Loe IM, Chirdkiatgumchai V, Kuan L, Gilman RC. Update on environmental risk factors for attention-deficit/hyperactivity disorder. Curr Psychiatry Rep 2011;13(5):333-44.

56. Huizink AC, Mulder EJ. Maternal smoking, drinking or cannabis use during pregnancy and neurobehavioral and cognitive functioning in human offspring. Neurosci Biobehav Rev 2006;30(1):24-41.

57. Hellström-Lindahl E, Seiger A, Kjaeldgaard A, Nordberg A. Nicotine-induced alterations in the expression of nicotinic receptors in primary cultures from human prenatal brain. Neurosci 2001;105(3):527-34.

58. Froehlich TE, Lanphear BP, Auinger P, Hornung R, Epstein JN, Braun J, et al. Association of tobacco and lead exposures with attention-deficit/hyperactivity disorder. Pediatrics 2009;124(6):e1054-e1063.

59. Cho SC, Kim BN, Hong YC, Shin MS, Yoo HJ, Kim JW, et al. Effect of environmental exposure to lead and tobacco smoke on inattentive and hyperactive symptoms and neurocognitive performance in children. J Child Psychol Psychiatry 2010;51(9):1050-7.

60. Rodriguez A, Bohlin G. Are maternal smoking and stress during pregnancy related to ADHD symptoms in children? J Child Psychol Psychiatry 2005;46(3):246-54.

61. Mick E, Biederman J, Faraone SV, Sayer J, Kleinman S. Case-control study of attention-deficit hyperactivity disorder and maternal smoking, alcohol use, and drug use during pregnancy. J Am Acad Child Adolesc Psychiatry 2002;41(4): $378-85$.

62. Button TM, Thapar A, McGuffin P. Relationship between antisocial behaviour, attention-deficit hyperactivity disorder and maternal prenatal smoking. Br J Psychiatry 2005;187:155-60.

63. Nomura Y, Marks DJ, Halperin JM. Prenatal Exposure to Maternal and Paternal Smoking on Attention Deficit Hyperactivity Disorders Symptoms and Diagnosis in Offspring. J Nerv Ment Dis 2010;198(9):672-8.

64. Motlagh MG, Katsovich L, Thompson N, Lin H, Kim YS, Scahill L, et al. Severe psychosocial stress and heavy cigarette smoking during pregnancy: an examination of the pre- and perinatal risk factors associated with ADHD and Tourette syndrome. Eur Child Adolesc Psychiatry 2010;19(10):755-64.

65. Hill SY, Lowers L, Locke-Wellman J, Shen SA. Maternal smoking and drinking during pregnancy and the risk for child and adolescent psychiatric disorders. J Stud Alcohol 2000; 61(5):661-8.

66. Nigg JT, Breslau N. Prenatal smoking exposure, low birth weight, and disruptive behavior disorders. J Am Acad Child Adolesc Psychiatry 2007;46(3):362-9.

67. Thapar A, Rice F, Hay D, Boivin J, Langley K, van den $\mathrm{Bree} \mathrm{M}$, et al. Prenatal smoking might not cause attention-deficit/hyperactivity disorder: evidence from a novel design. Biol Psychiatry 2009;66(8):722-7.

68. Lavigne JV, Hopkins J, Gouze KR, Bryant FB, LeBailly SA, Binns HJ, et al. Is Smoking During Pregnancy a Risk Factor for Psychopathology in Young Children? A Methodological Caveat 
and Report on Preschoolers. J Pediatr Psychol 2011;36(1): $10-24$.

69. Markussen Linnet KM, Obel C, Bonde E, Hove Thomsen P, Secher NJ, Wisborg K, et al. Cigarette smoking during pregnancy and hyperactive-distractible preschoolers: a follow-up study. Acta Paediatr 2006;95(6):694-700.

70. Kotimaa AJ, Moilanen I, Taanila A, Ebeling H, Smalley SL, McGough JJ, et al. Maternal smoking and hyperactivity in 8-year-old children. J Am Acad Child Adolesc Psychiatry 2003;42(7):826-33.

71. Obel C, Linnet KM, Henriksen TB, Rodriguez A, Järvelin MR, Kotimaa A, et al. Smoking during pregnancy and hyperactivity-inattention in the offspring - comparing results from three Nordic cohorts. Int J Epidemiol 2009;38(3):698-705.

72. Huijbregts SC, Séguin JR, Zoccolillo M, Boivin M, Tremblay RE. Associations of maternal prenatal smoking with early childhood physical aggression, hyperactivity-impulsivity, and their co-occurrence. J Abnorm Child Psychol 2007;35(2): 203-15.

73. Romano E, Tremblay RE, Farhat A, Côté S. Development and prediction of hyperactive symptoms from 2 to 7 years in a population-based sample. Pediatrics 2006;117(6):2101-10.

74. Day NL, Richardson GA, Goldschmidt L, Cornelius MD. Effects of prenatal tobacco exposure on preschoolers' behavior. J Dev Behav Pediatr 2000;21(3):180-8.

75. Höök B, Cederblad M, Berg R. Prenatal and postnatal maternal smoking as risk factors for preschool children's mental health. Acta Paediatr 2006;95(6):671-7.

76. Tremblay RE, Nagin DS, Séguin JR, Zoccolillo M, Zelazo PD, Boivin M, et al. Physical aggression during early childhood: trajectories and predictors. Pediatrics 2004;114(1):e43-50.

77. Batstra L, Hadders-Algra M, Neeleman J. Effect of antenatal exposure to maternal smoking on behavioural problems and academic achievement in childhood: prospective evidence from a Dutch birth cohort. Early Hum Dev 2003;75(1-2):21-33.

78. D'Onofrio BM, Van Hulle CA, Waldman ID, Rodgers JL, Harden KP, Rathouz PJ, et al. Smoking during pregnancy and offspring externalizing problems: an exploration of genetic and environmental confounds. Dev Psychopathol 2008;20(1): 139-64.

79. Brion MJ, Victora C, Matijasevich A, Horta B, Anselmi L, Steer $\mathrm{C}$, et al. Maternal smoking and child psychological problems: disentangling causal and noncausal effects. Pediatrics 2010;126(1):e57-65.

80. Lindblad F, Hjern A. ADHD after fetal exposure to maternal smoking. Nicotine Tob Res 2010;12(4):408-15.

81. Bos-Veneman NG, Kuin A, Minderaa RB, Hoekstra PJ. Role of perinatal adversities on tic severity and symptoms of attention deficit/hyperactivity disorder in children and adolescents with a tic disorder. J Dev Behav Pediatr 2010;31(2):100-6.

82. Thapar A, Fowler T, Rice F, Scourfield J, van den Bree M, Thomas $\mathrm{H}$, et al. Maternal smoking during pregnancy and attention deficit hyperactivity disorder symptoms in offspring. Am J Psychiatry 2003;160(11):1985-9.

83. Brook JS, Brook DW, Whiteman M. The influence of maternal smoking during pregnancy on the toddler's negativity. Arch Pediatr Adolesc Med 2000;154(4):381-5.

84. Brook DW, Zhang C, Rosenberg G, Brook JS. Maternal cigarette smoking during pregnancy and child aggressive behavior. Am J Addict 2006;15(6):450-6.

85. Ashford J, van Lier PA, Timmermans M, Cuijpers P, Koot HM. Prenatal smoking and internalizing and externalizing problems in children studied from childhood to late adolescence. J Am Acad Child Adolesc Psychiatry 2008;47(7): $779-87$.

86. Knopik VS. Maternal smoking during pregnancy and child outcomes: real or spurious effect? Dev Neuropsychol 2009;34(1):1-36.

87. Kelly SJ, Day N, Streissguth AP. Effects of prenatal alcohol exposure on social behavior in humans and other species. Neurotoxicology and Teratology 2000;22:143-9.

88. Jacobson JJ, Jacobson SW. Effects of prenatal alcohol exposure on child development. Alcohol Research and Health 2002;26(4):282-6. 
89. Bonthius DJ, West JR. Alcohol-induced neuronal loss in developing rats: increased brain damage with binge exposure. Alcohol Clin Exp Res 1990;14:107-18.

90. West JR, Goodlett CR, Bonthius DJ, Hamre KM, Marcussen BL. Cell population depletion associated with fetal alcohol brain damage: mechanisms of BAC-dependent cell loss. Alcohol Clin Exp Res 1990;14:813-18.

91. West JR, Kelly SI, Pierce DR. Severity of alcohol-induced deficits in rats during the first trimester equivalent is determined by the pattern of exposure. Alcohol 1987;Suppl 1:461-5.

92. Pratt OE. Introduction: what do we know of the mechanisms of alcohol damage in utero? Ciba Found Symp 1984;105:1-7.

93. Sood B, Delaney-Black V, Covington C, NordstromKlee B, Ager J, Templin T, et al. Prenatal alcohol exposure and childhood behavior at age 6 to 7 years: I. DoseResponse effect. Pediatrics 2001;108:e34. DOI: 10.1542/ peds.108.2.e34

94. Delaney-Black V, Covington C, Templin T, Ager J, NordstromKlee B, Martier S, et al. Teacher-assessed behavior of children prenatally exposed to cocaine. Pediatrics 2000;106(4):782-91.

95. Nigg JT. What causes ADHD? Understanding what goes wrong and why? New York: The Guilford Press; 2006.

96. Bellinger DC. Late Neurodevelopmental Effects of Early Exposures to Chemical Contaminants: Reducing Uncertainty in Epidemiological Studies. Basic Clin Pharmacol Toxicol 2008;102:237-44.

97. Faraone SV, Biderman J, Milberger S. How reliable are maternal reports of their children's psychopathology? One-year recall of psychiatric diagnoses of $A D H D$ children. $\mathrm{J}$ Am Acad Child Adolesc Psychiatry 1995;34(8):1001-8.

98. Cohen S, Doyle WJ, Baum A. Socioeconomic status is associated with stress hormones. Psychosom Med 2006;68: 414-20.

99. Gallo LC, Matthews KA. Understanding the association between socioeconomic status and physical health: do negative emotions play a role? Psychol Bull 2003;129:10-51.

100. Hougaard KS, Hansen AM. Enhancement of developmental toxicity effects of chemicals by gestational stress: A review. Neurotoxicol Teratol 2007;29:425-45.

101. Biederman J, Mick E, Faraone SV, Braaten E, Doyle A, Spencer T, et al. Influence of gender on attention deficit hyperactivity disorder in children referred to a psychiatric clinic. Am J Psychiatry 2002;159(1):36-42.

102. Newcorn JH, Halperin JM, Jensen PS, Abikoff HB, Arnold LE, Cantwell DP, et al. Symptom profiles in children with ADHD: Effects of comorbidity and gender. J Amer Acad Child Adolesc Psychiatry 2001;40:137-46.

103. Coe CL, Lulbach GR, Schneider ML. Prenatal disturbance alters the size of the corpus callosum in young monkeys. Dev Psychobiol 2002;41:178-85.

104. Staller J, Faraone SV. Attention-deficit hyperactivity disorder in girls: epidemiology and management. CNS Drugs 2006;20(2):107-23.

105. Hutchinson AD, Mathias JL, Banich MT. Corpus callosum morphology in children and adolescents with attention deficit hyperactivity disorder: A meta-analytic review. Neuropsychology 2008;22(3):341-9.

This work is available in Open Access model and licensed under a Creative Commons Attribution-NonCommercial 3.0 Poland License - http://creativecommons.org/ licenses/by-nc/3.0/pl/deed.en. 